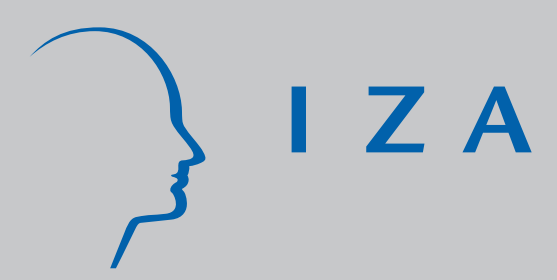

IZA DP No. 5845

Contractual Dualism, Market Power and Informality

Arnab K. Basu

Nancy H. Chau

Ravi Kanbur

July 2011

Forschungsinstitut

zur Zukunft der Arbeit

Institute for the Study

of Labor 


\title{
Contractual Dualism, Market Power and Informality
}

\author{
Arnab K. Basu \\ College of William and Mary \\ and IZA \\ Nancy H. Chau \\ Cornell University \\ and IZA \\ Ravi Kanbur \\ Cornell University \\ and IZA
}

\section{Discussion Paper No. 5845}

July 2011

IZA

P.O. Box 7240

53072 Bonn

Germany

Phone: +49-228-3894-0

Fax: +49-228-3894-180

E-mail: iza@iza.org

Any opinions expressed here are those of the author(s) and not those of IZA. Research published in this series may include views on policy, but the institute itself takes no institutional policy positions.

The Institute for the Study of Labor (IZA) in Bonn is a local and virtual international research center and a place of communication between science, politics and business. IZA is an independent nonprofit organization supported by Deutsche Post Foundation. The center is associated with the University of Bonn and offers a stimulating research environment through its international network, workshops and conferences, data service, project support, research visits and doctoral program. IZA engages in (i) original and internationally competitive research in all fields of labor economics, (ii) development of policy concepts, and (iii) dissemination of research results and concepts to the interested public.

IZA Discussion Papers often represent preliminary work and are circulated to encourage discussion. Citation of such a paper should account for its provisional character. A revised version may be available directly from the author. 


\section{ABSTRACT \\ Contractual Dualism, Market Power and Informality}

Two stylized representations are often found in the academic and policy literature on informality and formality in developing countries. The first is that the informal (or unregulated) sector is more competitive than the formal (or regulated) sector. The second is that contract enforcement is easier in the formal sector than in the informal sector, precisely because the formal sector comes under the purview of state regulation. The basic contention of this paper is that these two representations are not compatible with each other. We develop a searchtheoretic model of contractual dualism in the labor market where the inability to commit to contracts in the informal sector leads to employer market power in equilibrium, while an enforced minimum wage in the formal sector provides employers with a commitment technology but which reduces their market power in equilibrium. The contributions of this paper are three-fold. It (i) provides the micro-underpinnings for endogenous determination of employer market power in the formal and informal sectors due to contractual dualism in the two sectors, (ii) offers a unified and coherent setup whereby a host of salient features of developing country labor markets can be explained together, and (iii) places the original Stiglerian prescription of the optimal (unemployment minimizing) minimum wage in the broader context of labor markets where formal job creation is costly, and where formal employment, informal employment, and unemployment co-exist.

JEL Classification: J3, J6, O17

Keywords: contractual dualism, wage dualism, employer market power, informality

Corresponding author:

Nancy H. Chau

Charles H. Dyson School of Applied Economics and Management

Cornell University

Ithaca, NY 14853

USA

E-mail: hyc3@cornell.edu

\footnotetext{
" We thank Gary Fields, Santiago Levy, and seminar participants at Cornell, the Federal Reserve Bank at St. Louis, the Inter-American Development Bank, and the Institute for the Study of Labor (IZA) for helpful comments and stimulating discussions.
} 


\section{Introduction}

Economic activities in developing countries are often classified as falling into either a state regulated sphere or an unregulated sphere. ${ }^{1}$ The labels "formal" and "informal" are often attached to these spheres or sectors, it being understood of course that in reality there is a continuum rather than a dichotomy. The dualistic formulation is nevertheless useful conceptually in capturing key characteristics for analytical or policy discourse. The literature on formality and informality is large and diverse, with many controversies, even down to whether the terms themselves are appropriate. ${ }^{2}$ However, two features of these sectors, or rather two contrasts between them, seem to be generally accepted in different parts of the literature.

First the informal sector is seen as being competitive, with no market power or dominance by a group of actors or by one side of the market, particularly in the labor market; the formal sector, on the other hand, is seen as having elements of market power, whether it be large firms or labor unions. Such characterizations are a staple of the development economics literature, and have distinctive policy conclusions targeted toward the lack of competition in the formal sector. Reducing union power in formal sector labor markets, or removing minimum wage legislation or other regulation in these markets, are typical policy conclusions that flow from such a perspective. ${ }^{3}$

Second, enforcement of contracts is seen as being particularly difficult in the informal sector. This in turn leads to calls for extending the realm of formal regulation and law, which is seen as being able to "unlock the economic potential" of the informal sector. Major policy initiatives, such as property titling in urban slums, flow from these initiatives. ${ }^{4}$

The basic contention of this paper is that these two views - stated in sharp form as (i) the informal sector is competitive and (ii) contract enforcement is not possible in the informal sector - are incompatible. Indeed, we argue that the lack of contract enforcement leads to

\footnotetext{
${ }^{1}$ The pervasiveness of the unregulated sphere has been well documented. For example, Schneider and Enste (2000) finds, using a multitude of methods, that the average size of the informal sector as a percentage of GDP ranges from 23 percent for transition countries to 39 percent for developing countries.

${ }^{2}$ See Guha-Khasnobis, Kanbur and Ostrom (2006) and Kanbur (2009) for the latest in many surveys of the literature.

${ }^{3}$ For example, The Economist (September 11 - 17, 2010), in its survey of Latin America, notes: "Thanks largely to baroque regulation, half the labour force toils in the informal economy, unable to reap the productivity gains that come from technnology and greater scale." See also Levy (2007). A classic exposition of such dualism is to be found in Harris and Todaro (1970).

${ }^{4}$ The best known proponent of this position is de Soto (2003).
} 
the development of market power in equilibrium. We establish these claims by focusing on a model of the labor market where wages are paid after the work is done, but employers cannot commit to wage contracts. There is then a holdup problem because workers cannot be sure they will get paid for the work they have done. We argue that equilibrium is then characterized by employer market power even with free entry, because any attempts by newcomers to bid labor away with higher wages cannot be credible in the absence of enforceable contracts. In this setting, third party enforcement, such as a state enforced minimum wage floor, alleviates the holdup problem and offers a de facto commitment device leading to greater efficiency, and contributes to greater equity as well.

Consider now a situation where the government's writ does not run throughout the economy, and firms can choose between being in the regulated and the unregulated sector. In the unregulated portion of the economy, wage contracts are not enforceable by third parties, so that only those contracts that are self-enforcing are viable. In the regulated sector, firms face costly job creation / registration costs, in addition to an enforced minimum wage. In the conventional view of the formal sector, these regulations are a costly burden for firms. But in our model, we offer an alternative interpretation, where signing up as a formal firm signals an employer's (state enforced) commitment to pay a high wage.

With this structure we describe and characterize an equilibrium where the division of activity between the informal and formal sectors is determined endogenously. We show that market power of employers is greater in the informal sector than in the formal sector - informal is less competitive than formal despite, or actually because of, non-enforcement of contracts.

The importance of limited commitment in determining labor market outcomes has been discussed in a number of other settings. For example, Shapiro and Stiglitz (1984) studies the implications of inability on the part of workers to make a prior commitment on effort. Chari, Restuccia and Urrutia (2005) sets out to determine the implications of worker's inability to commit to stay on the job. Ramey and Watson (1997) examines the implications of two-sided limited commitments on the part of both workers and employers to refrain from shirking. The power of these and related studies lies in their ability to provide a coherent explanation for observed salient features of labor markets that are not easily explained in a setting otherwise free 
from commitment problems,${ }^{5}$ as well as in their ability to offer innovative policy conclusions. ${ }^{6}$

What is particularly notable here, however, is that the focus of this earlier literature and the associated policy conclusions typically target developed country labor markets. In this paper, we propose a model of contractual dualism in the formal and informal sectors that yields predictions consistent with five salient features of developing country labor markets that have received a good deal of attention: ${ }^{7}$

- Given skill level, formal sector wages are higher than in the informal sector.

- Some wages in the informal sector are above the formal sector minimum wage despite no requirement for them to be so.

- The national wage distribution will have a spike at the minimum wage.

- Co-movements of subminimum wages and the regulated minimum wage have been demonstrated, including positive correlations, no significant correlations, and negative correlations (Card and Krueger 1995, Lemos 2004, Baanante 2005, Strobl and Walsh 2001, Gindling and Terrell, 2002). ${ }^{8}$

- Skill levels in the formal and informal sectors will overlap, but the average skill level is higher in the formal sector (Maloney 1999, 2004, Thomas 1992, Gong and Van Soest 2002 and Gong, Van Soest and Villagomez 2004).

\footnotetext{
${ }^{5}$ Some of these include the existence of equilibrium unemployment (Shapiro and Stiglitz (1984), seniority based wages, high separation rates for low skilled workers (Chari, Restuccia and Urrutia (2005), and countercyclical job destruction without real wage rigidities (Ramey and Watson (1997)).

${ }^{6}$ Shapiro and Stiglitz (1984) proposes a tax on profits to fund wage subsidies, Chari, Restuccia and Urrutia proposes raising firing costs to increase duration of employer-worker matches, and Ramey and Watson (1997) provides the rationale for a severence Tax / Tax on firms following good states, to finance firms following bad states.

${ }^{7}$ Bargain and Kwenda (2010) demonstrates the existence of an informal wage penalty using evidence from Brazil, Mexico, and South Africa. Charlot, Malherbet and Terra (2011) likewise presents evidence from Brazil indicating a wage premium in the formal sector after controlling for individual characteristics. For studies that present kernel density plots and / or wage histograms of dispersed subminimum wage distribution, see for example, Bell (1997) for Colombia, Maloney and Nunez (2004) for eight Latin American countries, Cardoso and Portugal (2005) for Portugal, Terrell and Gindling (2006) for Honduras, Strobl and Walsh (2001) for Trinidad and Tobago, Lemos (2004) for both the formal and informal sectors in Brazil. These studies likewise demonstrate wage dualism between the formal and informal sectors, the overlap of wage distributions in the two sectors, over compliance in the informal sector, and a spike of the wage distribution at the minimum wage.

${ }^{8}$ Our model also predicts an inverted-U shaped relationship between the minimum wage and employment. Empirical studies on the employment effects of higher minimum wages have likewise generated mixed results to date. See for example, Fanzylber (2001) and Carneiro and Corseuil (2001), showing positive employment effect of a minimum wage on the informal sector. Maloney and Nunez (2004), for example, finds the employment effect to be negative. Other studies find no significant relationship (Lemos 2009, Gindling and Terrell 2007).
} 
In terms of policy implications, we propose a simple formula that revises the Stiglerian prescription of an optimal (unemployment minimizing) minimum wage. The original prescription stipulates a skill-specific minimum wage, to be set at the marginal value product of laborers in an otherwise competitive labor market (Stigler 1946). Our extension of the optimal minimum wage formula - in a setting with endogenous employer market power induced by contractual dualism in the formal and the informal sectors - takes the Stiglerian prescription as a special case, and more generally incorporates the cost of creating a formal sector job as a key determinant of the height of such a minimum wage. Importantly, as has been recently demonstrated in Djankov et al. (2002), these costs of formal sector regulation can be significant. In the context of our analysis, the implication is thus that the corresponding downward adjustment required in setting the unemployment minimizing minimum wage relative to the marginal value product of labor will accordingly be substantial. Put another way, the cost of formal sector job creation puts a strict limit on the extent to which a government enforced minimum wage can simultaneously achieve efficiency (raising employment) and distributional (raising wages) gains.

In summary, the contributions of this paper are three-fold. It (i) provides the microunderpinnings for endogenous determination of employer market power in the formal and informal sectors due to contractual dualism in the two sectors, (ii) offers a unified and coherent setup whereby a host of salient features of developing country labor markets can be explained together, and (iii) places the original Stiglerian prescription of the optimal (unemployment minimizing) minimum wage in the broader context of labor markets where formal job creation is costly, and where formal employment, informal employment, and unemployment co-exist.

This paper is also related to a large literature on the informal economy. Fields (2006) provides an excellent survey of multisectoral models of developing country labor markets where the wage, formal and informal employment, in addition to unemployment implications of policy shifts can be ascertained. It is noteworthy that this class of models typically assumes that labor markets in both the formal and informal sectors are competitive, thus effectively ruling out unemployment-reducing and equity-improving minimum wage reforms à la Stigler (1946).

Our model is search theoretic in nature. There has been a surge in attention given to models of the informal sector using a search theoretic approach where match frictions play an 
important role. For example, Zenou (2008) examines the employment impacts of unemployment benefits, wage subsidies, and entry costs in the formal sector, and does so in a setting which assumes a frictionless informal labor market, and a formal labor market characterized by search friction and unemployment. Albrecht, Navarro and Vroman (2011) presents a search and matching model of a regulated formal and an unregulated informal sector where the size, as well as skill composition of the formal and informal workforce adjust endogenously to severance and payroll taxes. Boeri and Garibaldi (2006) is likewise concerned with the skill composition of the formal and informal workforce, as well as the puzzling increase in size of the shadow economy despite improvements in detection technologies against tax evasion. Charlot, Malherbet and Terra (2011) departs further from the standard search theoretic setup by permitting product market price setting behavior by formal and informal firms, and examines the impact of entry costs and workers' bargaining power on employment, unemployment and wage bargaining outcomes in the formal and informal sectors.

In our paper, search related labor market frictions will likewise be one of the building blocks of the model. But departing from these existing studies, our paper introduces a contractual view to wage and employer market power formation in the formal and the informal labor markets. We demonstrate that such a setting provides a coherent basis for understanding a wide variety of salient features related to differences in skill composition, wage distribution, and regulation compliance commonly observed in the formal and informal sectors of developing countries that cannot be easily explained together. In terms of policy implications, this paper provides a simple formula which links the cost of job creation in the formal sector, known to be substantial in many developing countries, and the size of the optimal minimum wage.

The plan of the paper is as follows. Section 2 develops the basic search framework where all labor contracts are subject to a No Reneging Constraint (NRC). A steady state equilibrium where formal and informal sectors co-exist is then characterized, and the features of this equilibrium are explored. Section 3 considers the special case of a non intervention benchmark, where there is no minimum wage in the economy. In this case, the model collapses to a single sector. It is shown that in this equilibrium, employers have market power despite free entry, with consequent inefficiency of outcomes. Section 4 focuses on minimum wage policy with contractual dualism. We show how the equilibrium changes with the minimum wage, and 
furthermore the lowest minimum wage that eliminates employer market power in fact coincides with the lowest minimum wage that minimizes unemployment. Section 5 concludes with some observations on further research.

\section{The Model}

Let time $t$ be discrete, with $t=0,1,2, \ldots, \infty$. We consider a labor market with a large pool of workers $(\bar{N})$. The skill level of workers is parameterized by $a \geq 0$, and the exogenously given number of workers with skill level $a$ is $\bar{N}(a)$. The discounted lifetime utility of a worker takes the form:

$$
W_{\tau}=\sum_{t=0}^{\infty} \beta_{N}^{t} y_{t+\tau}
$$

where $y_{t}$ is income at time $t$ and workers' discount factor is given by $\beta_{N} \in(0,1)$. Let $\bar{u}<a$ denote unemployment income.

Let $M(a)$ denote the endogenous number of employers in search of skill type $a$ workers. The objective of an individual employer is to maximize the discounted sum of profits:

$$
\pi_{\tau}=\sum_{t=0}^{\infty} \beta_{E}^{t} \pi_{t+\tau}
$$

over the infinite horizon, where $\beta_{E}$ denotes employers' discount factor.

An employer can choose between operating in the formal or the informal sector. A match between an employer and a skill type $a$ worker in either sector generates revenue $a$ per period. The size of every firm in this setting is exactly one worker. ${ }^{9}$

We say that production takes place in the formal sector if two conditions are met. First, a fixed cost of formal job creation $\rho_{f} a$ applies, covering the cost of worker search, the cost of registration, and the cost of overcoming any other bureaucratic roadblocks that undermine job creation. We take the fixed cost of entry to be increasing in the value of the final output $a$, where $\rho_{f}$ is a strictly positive fraction. ${ }^{10}$

Second, formal employers obey a government mandated minimum wage $\bar{w}$. We consider minimum wages in the range $(\bar{u}, a)$. The minimum wage is strictly enforced by third party

\footnotetext{
${ }^{9}$ We thus abstract from variations in firm size as shown in Rauch (1991) for example, and focus instead on limited commitment, market power, as well as the five salient skill composition and wage distribution features of developing economies - features that have yet to receive systematic treatment in the literature.

${ }^{10}$ In section 4 , we discuss the relevance of $\rho_{f}$ both in empirical studies of the cost of formal sector entry, and in the determination of an optimal minimum wage in this setup.
} 
government enforcement agencies. The expected wage bill upon hiring a skill type $a$ worker at contracted formal sector wage $w_{f}$ is:

$$
w_{f}^{e}\left(a, w_{f}, \bar{w}\right)=w_{f}+\max \left\{\bar{w}-w_{f}, 0\right\} .
$$

The creation of an informal sector job also involves a fixed cost $\rho_{i} a$, where $0<\rho_{i}<\rho_{f}$, reflecting the cost savings of operating informally. The absence of official registration however renders the minimum wage harder to enforce in the informal sector. Let $q \in[0,1)$ be the government enforcement intensity. The expected wage bill at any contracted informal sector wage $w_{i}$ is

$$
w_{i}^{e}\left(a, w_{i}, \bar{w}\right)=w_{i}+q \max \left\{\bar{w}-w_{i}, 0\right\} .
$$

\subsection{Search Friction with a Formal and an Informal Sector}

At the start of each time period, an employer in search of a worker of skill level $a$ chooses and proposes an expected offer $w^{e}$ to one of $U(a)$ number of $a$-type unemployed job seekers chosen at random. Let $F\left(w^{e} ; a, \bar{w}\right)$ be the cumulative distribution function of such employer offers conditional on skill type $a . F\left(w^{e} ; a, \bar{w}\right)$ is taken to be inclusive of both formal and informal wage offers so long as they are targeted towards workers of skill type $a$. We assume in addition that a job offer lasts at most one period, and there is no possibility of recall of previously unaccepted offers.

Each job seeker rates any and all offers received, selects the best, and rejects the rest. We assume that search friction prevents the job seeker from receiving the full set of offers. Instead, the likelihood that an unemployed job seeker is met with $z=0,1,2, \ldots$ offers is given by a Poisson distribution with parameter $\lambda(a)=M(a) / U(a)$, or, $\operatorname{Pr}(z ; \lambda(a))=e^{-\lambda(a)} \lambda(a)^{z} / z$ ! (Mortensen 2003). Since the distribution of each such wage offer is $F\left(w^{e} ; a, \bar{w}\right)$, the cumulative distribution of the maximal offer received is:

$$
H\left(w^{e} ; a, \bar{w}\right) \equiv \sum_{z=0}^{\infty} \frac{e^{-\lambda(a)} \lambda(a)^{z} F\left(w^{e} ; a, \bar{w}\right)^{z}}{z !}=e^{-\lambda(a)\left(1-F\left(w^{e} ; a, \bar{w}\right)\right)} .
$$

$H\left(w^{e} ; a, \bar{w}\right)$ gives the probability that the best offer that a skill type $a$ worker receives is less than $w^{e}$. From an employer's perspective, $H\left(w^{e} ; a, \bar{w}\right)$ is thus the likelihood of consummating a match with a skill type $a$ worker by offering $w^{e}$. 


\section{Workers}

At any time $t$, there are two groups of workers: those who are unemployed $U(a)$, and those who are employed $N(a)=\bar{N}(a)-U(a)$. Among employed workers, there is in addition an endogenous division between informal $\left(N_{i}(a)\right)$ and formal sector workers $\left(N_{f}(a)\right)$. By definition of workers' preference $W_{\tau}$, each worker cares only about the discounted utility of take home income $y_{t}$, but not the sector from which this income is derived per se. Thus, we denote $W\left(w^{e}, a, \bar{w}\right)$ as the value function of an employed worker given $w^{e}$, and $W^{u}(a, \bar{w})$ the value function of an unemployed worker.

An employed worker at time period $t$ receives his expected income $w^{e}$, and faces two possible prospects in the following period at $t+1$ : (i) continue on with the same job, or (ii) transition into unemployment. We assume that $\delta>0$ is an exogenous probability of separation. Thus

$$
\begin{aligned}
W\left(w^{e}, a, \bar{w}\right) & =w^{e}+\beta_{N}\left[\delta W^{u}(a, \bar{w})+(1-\delta) W\left(w^{e}, a, \bar{w}\right)\right] \\
& =\frac{w^{e}+\beta_{N} \delta W^{u}(a, \bar{w})}{1-b_{N}}
\end{aligned}
$$

$b_{N}=\beta_{N}(1-\delta)$ henceforth denotes the separation risk adjusted discount factor. The value function of an unemployed skill type $a$ worker is given by:

$$
W^{u}(a, \bar{w})=\bar{u}+\beta_{N} \int_{x} \max \left\{W(x, a, \bar{w}), W^{u}(a, \bar{w})\right\} d H(x ; a, \bar{w})
$$

where the worker receives his unemployment income $\bar{u}>0$ in the current period, and anticipates the choice between staying unemployed, or accepting his best offer in the following period. ${ }^{11}$

From $(4), W\left(w^{e}, a, \bar{w}\right)$ is monotonically increasing in $w^{e}$. Thus let $w_{r}^{e}$ be the reservation expected take home pay - the lowest pay $w^{e}$ such that a worker is better off working than remaining unemployed:

$$
w_{r}^{e}(a)=\min \left\{w^{e}(a) \mid W^{e}\left(w^{e}, a, \bar{w}\right) \geq W^{u}(a, \bar{w})\right\} .
$$

\footnotetext{
${ }^{11}$ Though we will refer to $\bar{u}$ as unemployment income throughout this paper, we note here that $\bar{u}$ may also be interpreted as self-employment income, including any relevant government assistance available to unemployed / self-employed individuals.
} 
By monotonicity in (4), $w_{r}^{e}(a)$ is uniquely defined given $W^{u}(a, \bar{w})$. We have thus ${ }^{12}$

$$
W^{u}(a, \bar{w})=\bar{u}+\beta_{N}\left[\int_{w_{r}^{e}(a)}^{\infty} W(x, a) d H(x ; a, \bar{w})+H\left(w_{r}^{e}(a) ; a, \bar{w}\right) W^{u}(a)\right],
$$

which yields

$$
w_{r}^{e}(a, \bar{w})=\bar{u}+\frac{\beta_{N}}{1-b_{N}} \int_{w_{r}^{e}(a)}^{\infty}\left(x-w_{r}^{e}(a, \bar{w})\right) d H(x ; a, \bar{w}) .
$$

The reservation offer $w_{r}^{e}(a, \bar{w})$ implicitly solves $(7)$. Intuitively, $w_{r}^{e}(a, \bar{w})$ is equal to the unemployment income, plus the (separation risk adjusted) discounted income gains that an unemployed worker can expect upon delaying employment for one more period. With this in mind, we henceforth normalize $\bar{u}$ at zero.

\section{Employers}

There are two groups of employers at any time $t$. Those already employing an existing worker, and those seeking a new worker. For employers in the first group employing a skill type $a$ worker, let $V_{j}\left(w^{e}, a\right)$ denote the associated value function for an employer in sector $j=i, f .{ }^{13}$ Given any accepted offer $w^{e}$, the employer earns current period expected profit $a-w^{e}$, and faces two possibilities in the following period: ${ }^{14}$ continuation of the same labor contract $w^{e}$ for one more period, at expected value $V\left(w^{e}, a\right)$ with probability $1-\delta$, or separation otherwise, with zero profits thereafter. Thus:

$$
\begin{aligned}
V_{j}\left(w^{e}, a\right) & =a-w^{e}+\beta_{E}(1-\delta) V_{j}\left(w^{e}, a\right) \\
& =\frac{a-w^{e}}{1-b_{E}}
\end{aligned}
$$

where $b_{E} \equiv \beta_{E}(1-\delta)$. For employers in search of a worker at skill level $a$ offering $w^{e} \geq w_{r}^{e}(a, \bar{w})$, the associated value functions $\left(V_{i}^{o}\right.$ and $\left.V_{f}^{o}\right)$ account for the match likelihood $H\left(w^{e} ; a, \bar{w}\right)$, and

\footnotetext{
${ }^{12}$ Equation (7) follows from (4) - (6), where$$
W\left(w_{r}^{e}, a, \bar{w}\right)=\frac{w_{r}^{e}+\beta_{N} \delta W^{u}(a, \bar{w})}{1-b}=W^{u}(a, \bar{w}) \Leftrightarrow W^{u}(a, \bar{w})=w_{r}^{e} /\left(1-\beta_{N}\right) .
$$

In other words, the lifetime discounted value of a stream of income equaling the reservation offer $w_{r}^{e}$ gives the value function of the unemployed. Substituting the above to (4) gives (7).

${ }^{13}$ From (1) and (2), the implied contracted wage $w_{f}$ in the formal sector solves $w^{e}(a)=w_{f}+\max \left\{\bar{w}-w_{f}, 0\right\}$, while the same expected wage $w^{e}$ in the informal sector implies a contracted wage $w_{i}$ that solves $w^{e}=w_{i}+$ $q \max \left\{\bar{w}-w_{i}, 0\right\}$ given government enforcement intensity $q$.

${ }^{14}$ To see this, note that given the probability of detection $q$, current period expected profit of an informal employer is simply $a-w-q \max \{\bar{w}-w, 0\}$, or, $a-w^{e}$ as stated.
} 
the job creation costs $\rho_{i} a$ and $\rho_{f} a$ in the two sectors:

$$
\begin{aligned}
V_{i}^{o}\left(w^{e}, a, \bar{w}\right) & =H\left(w^{e} ; a, \bar{w}\right) V_{i}\left(w^{e}, a\right)-\rho_{i} a \\
V_{f}^{o}\left(w^{e}, a, \bar{w}\right) & =H\left(w^{e} ; a, \bar{w}\right) V_{f}\left(w^{e}, a\right)-\rho_{f} a .
\end{aligned}
$$

Armed with (8) and (9), the decision problem of an employer is two-fold: (i) choose between offering a formal or an informal sector job, and (ii) select an expected take home pay $w^{e}$ to offer. Answers to these questions will give the equilibrium wage distribution at each skill level, the endogenous division of informal and formal sector jobs along the wage distribution, and the associated reservation wage from (7). To these ends, we proceed next to discuss the implications of three sets of demand side constraints facing employers in their wage offer choices.

\section{$2.2 \quad$ Free Entry and Self-Enforcing Contracts}

\section{Minimum Wage Constraint (MWC)}

This first constraint establishes the minimum expected offer that an employer will need to make in the presence of a minimum wage. For all non-negative contracted formal wage $w_{f} \geq 0$,

$$
w^{e}=w_{f}+\max \left\{\bar{w}-w_{f}, 0\right\} \geq \bar{w} \equiv w_{f}^{M W}(\bar{w}) .
$$

Not surprisingly, with a perfectly enforced minimum wage, formal expected wage offer is no less than the minimum wage. Similarly in the informal sector, for all non-negative contracted wage $w_{i} \geq 0$,

$$
w^{e}=w_{i}+q \max \left\{\bar{w}-w_{i}, 0\right\} \geq q \bar{w} \equiv w_{i}^{M W}(\bar{w})
$$

and the informal expected wage offer should never fall below the government enforced expected wage $q \bar{w}$. Figure 1a illustrates.

\section{Free Entry Constraint (FEC)}

With free entry, the highest expected wage offer that an employer can afford must at least sustain non-negative expected profits, $V_{i}^{o}$ and $V_{f}^{o}$. Thus, let $w_{i}^{F E}(a)$ and $w_{f}^{F E}(a)$ be these skillspecific maximal offers respectively in $i$ and $f$. Suppose that the highest offer $w^{e}$ among skill type $a$ workers is made in the informal sector at $w_{i}^{F E}(a)$, the match likelihood of the highest 
offer is $H\left(w_{i}^{F E} ; a, \bar{w}\right)=1$ for there exist by definition no other offers that outmatch $w_{i}^{F E}(a)$. The associated value function is thus:

$$
V_{i}^{o}\left(w_{i}^{F E}(a), a, \bar{w}\right)=\frac{a-w_{i}^{F E}(a)}{1-b_{E}}-\rho_{i} a, \Leftrightarrow w_{i}^{F E}(a)=\left[b_{E}+\left(1-b_{E}\right)\left(1-\rho_{i}\right)\right] a \equiv \theta_{i} a .
$$

By similar reasoning if instead the best offer among skill type $a$ workers occurs in the formal sector at $w_{f}^{F E}(a)$, it follows now that $H\left(w_{f}^{F E} ; a, \bar{w}\right)=1$, and

$$
V_{f}^{o}\left(w_{f}^{F E}(a), a, \bar{w}\right)=\frac{a-w_{f}^{F E}(a)}{1-b_{E}}-\rho_{f} a, \Leftrightarrow w_{f}^{F E}(a)=\left[b_{E}+\left(1-b_{E}\right)\left(1-\rho_{f}\right)\right] a \equiv \theta_{f} a .
$$

Clearly, the higher the skill level, the higher the maximal offers $w_{i}^{F E}(a)$ and $w_{f}^{F E}(a)$. In both sectors, the highest wage consistent with zero expected profits is a fraction of the marginal productivity $a$ in the presence of strictly positive job creation costs. Furthermore, since job creation cost is strictly higher in the formal sector, we have

Proposition 1 With free entry in the formal and the informal sector,

$$
w_{f}^{F E}(a) \leq w_{i}^{F E}(a)
$$

Higher job creation cost in the formal sector thus translates to lower wage offers when the free entry constraint binds. This puts formal sector employer at a disadvantageous position in their bid for workers. This is illustrated in Figure 1b, which plots $w_{f}^{F E}(a)$ and $w_{i}^{F E}(a)$ across skill types.

\section{No Reneging Constraint (NRC)}

Unless there is perfect enforcement by third party agencies, credible labor contracting must also be self-enforcing. We identify two "No Reneging Constraints" (NRC), one for each sector. The NRC ensures that an employer prefers paying the contracted wage over reneging on a labor contract that has been struck. We assume that a refusal to honor the contracted payment leads to a worker initiated termination of the employment relation. ${ }^{15}$ Thus, a wage offer $w^{e}$ targeting a skill type $a$ worker satisfies the NRC in the informal sector if and only if

$$
V_{i}\left(w^{e}, a\right)=a-w^{e}+\beta_{E}(1-\delta) V_{i}\left(w^{e}, a\right) \geq a-q \max \{\bar{w}-0,0\}=a-q \bar{w}
$$

\footnotetext{
${ }^{15}$ In a steady state, an employer that reneges in one period will renege in subsequent periods. A punishment that leads to employment termination is rational from the workers' point of view for $W^{u}(a) \geq 0$ from (5).
} 
where $a-q \min \{\bar{w}, a\}$ is the expected profit of a reneging employer, who derives labor $a$ from the contracted worker, pays $\min \{\bar{w}, a\}$ only if discovered by enforcement agencies (with probability $q$ ), and otherwise refuse to pay the contracted wage $w$ consistent with the offer $w^{e}=w+q \max \{\bar{w}-w, 0\}$.

Similarly, the NRC in the formal sector requires

$$
V_{f}\left(w^{e}, a\right)=a-w^{e}+\beta_{E}(1-\delta) V_{f}\left(w^{e}, a\right) \geq a-\max \{\bar{w}-0,0\}=a-\bar{w}
$$

where $a-\bar{w}$ is the expected profit of a reneging formal sector employer, with government mandated minimum wage at $\bar{w}>0$.

The maximal self-enforcing offers that the two sectors can deliver are:

$$
\begin{aligned}
& w_{i}^{N R}(a, \bar{w})=\max \left\{w^{e} \mid V_{i}\left(w^{e}, a\right) \geq a-q \max \{\bar{w}-0,0\}\right\}=b_{E} a+\left(1-b_{E}\right) q \bar{w} \\
& w_{f}^{N R}(a, \bar{w})=\max \left\{w^{e} \mid V_{f}\left(w^{e}, a\right) \geq a-q \max \{\bar{w}-0,0\}\right\}=b_{E} a+\left(1-b_{E}\right) \bar{w} .
\end{aligned}
$$

Note that $w_{i}^{N R}(a, \bar{w})$ and $w_{f}^{N R}(a, \bar{w})$ are now weighted averages of the full output per worker $a$, and the expected government enforced wage, $q \bar{w}$ and $\bar{w}$ respectively in the two sectors. Intuitively, and in the absence of a minimum wage, $w_{i}^{N R}=w_{f}^{N R}$ is but a fraction $b_{E}$ of the marginal productivity $a$, which equates the one time profit of a reneging employer $(a)$, with the discounted profit of a non-reneging employer $\left(a-w_{i}^{N R}\right) /\left(1-b_{E}\right)=\left(a-w_{f}^{N R}\right) /\left(1-b_{E}\right)$ over the infinite horizon. Introducing the minimum wage raises $w_{f}^{N R}$ disproportionately more, since the lowest expected wage that even a reneging employer will be enforced by law to pay is $\bar{w}$ in the formal sector, and $q \bar{w}$ in the informal. Put differently, the potential wage gains from reneging, all else equal, is strictly less in the formal sector thanks to government enforcement of the minimum wage.

The NRC accordingly marks all wage offers higher than $w_{i}^{N R}$ and $w_{f}^{N R}$ as outside of the range of feasible wages, because workers harboring rational expectations will reject these high wage promises as not credible. These maximal wages are illustrated in Figure 1c, from which it immediately follows that

Proposition 2 With self-enforcing labor contracting in the formal and informal sectors,

$$
w_{f}^{N R}(a, \bar{w})>w_{i}^{N R}(a, \bar{w})
$$


In addition, both $w_{f}^{N R}(a, \bar{w})$ and $w_{i}^{N R}(a, \bar{w})$ are non-decreasing functions of $\bar{w}$, with

$$
w_{f}^{N R}(a, \bar{w}) \geq \bar{w}, \text { and } w_{i}^{N R}(a, \bar{w}) \geq q \bar{w} .
$$

In sharp contrast to the FEC, Figure 1c shows that the maximal wage in the formal sector now dominates that of the informal sector, thanks specifically to better enforcement of the minimum wage in the formal sector. Moreover, the self-enforcing maximal wage offers are higher than the government enforced expected wages: $\bar{w}$ and $q \bar{w}$ in the two sectors. The key insight here is that the profits of those who renege $(a-\bar{w}$ and $a-q \bar{w}$ respectively whenever $a>\bar{w}$ ) are kept in check by government enforcement of the minimum wage. This effectively enhances the employer's ability to sign self-enforcing labor contracts at wages even higher than the government enforced $\bar{w}$ and $q \bar{w}{ }^{16}$

\subsection{Contractual Dualism and Wage Dualism}

The juxtaposition of the MWC, the FEC, and the NRC determines the demand side of this labor market accommodating both informal and formal jobs. Between the two types of jobs, the key distinguishing feature is the intensity with which the government is able to impact the self-enforcement of private contracts by enforcing the minimum wage. Henceforth, we say that contractual dualism prevails whenever the enforcement intensities in the two sectors are sufficiently divergent. Specifically:

Definition 1 The labor market exhibits contractual dualism if and only if the discounted expected profits of an informal employer with a self-enforcing offer $w_{i}^{N R}(a, \bar{w})$ is always strictly positive: $V_{i}\left(w_{i}^{N R}(a, \bar{w}), a\right)-\rho_{i} a>0$, or equivalently ${ }^{17}$

$$
q<\left(1-\rho_{i}\right)
$$

Note that with full enforcement in the formal sector, the corresponding value function of a formal employer, $-\rho_{f} a$, is of course always negative since $w_{f}^{N R}(a, a)=a$. Contractual dualism includes of course the special case of $q=0$, where there is a complete absence of minimum wage enforcement in the informal sector.

\footnotetext{
${ }^{16}$ When the minimum wage exceeds $a$, further increases will of course have no further impact on the $w_{i}^{N R}(a, \bar{w})$.

${ }^{17}$ To see this, note that $V_{i}\left(w_{i}^{N R}(a, \bar{w}), a\right)-\rho_{i} a=a\left(1-\rho_{i}\right)-q \bar{w} \geq \bar{w}\left(1-\rho_{i}-q\right)>0$ if $q<1-\rho_{i}$ as shown, for all $\bar{w} \leq a$.
} 
Assume therefore that indeed $q<1-\rho_{i}$, Figure 2 illustrates the three constraints, and reveals the endogenous division between workers with informal and / or formal sector job prospects, along with the range of feasible expected wage offers anywhere along the skill spectrum $a \geq 0$. As shown, formal labor demand does not exist for skill levels that are sufficiently low $\left(<\bar{w} / \theta_{f}\right)$, for the set of feasible expected wage offers satisfying all three constraints in the formal sector is empty. Everywhere else, formal and informal demand for workers co-exist.

In terms of wages, the bold line labeled $w_{i}^{+}(a, \bar{w})$ in Figure 2 traces out the maximal informal offers satisfying all three constraints: the FEC $\left(w^{e} \leq w_{i}^{F E}\right)$, the NRC $\left(w^{e} \leq w_{i}^{N R}\right)$ and the MWC $\left(w^{e} \geq w_{i}^{M W}\right)$. The bold line labeled $w_{f}^{+}(a, \bar{w})$ does the same thing for the formal sector, incorporating the FEC $\left(w^{e} \leq w_{f}^{F E}\right)$, the $\mathrm{NRC}\left(w^{e} \leq w_{f}^{N R}\right)$, and the MWC $\left(w^{e} \geq w_{f}^{M W}\right)$. Let the maximal offer for skill type $a$ consistent with the application of the MWC, the FEC and the NRC in both sectors be given by

$$
w^{+}(a, \bar{w})=\max \left\{w_{i}^{+}(a, \bar{w}), w_{f}^{+}(a, \bar{w})\right\}
$$

where $w^{+}(a, \bar{w})$ is given by $w_{f}^{N R}, w_{f}^{F E}, w_{i}^{N R}$, respectively for $a>\bar{w} /\left(1-\rho_{f}\right), a \in\left[\bar{w} / \theta_{f}, \bar{w} /(1-\right.$ $\left.\rho_{f}\right)$ ), and $a<\bar{w} / \theta_{f}$. The lower bound informal and formal sector offers from the demand perspective are $w_{i}^{M W}$ and $w_{f}^{M W}$ respectively. As should be expected, contractual dualism is closely related to a binding NRC in the informal sector. By inspection of Figure 2

Proposition 3 Contractual dualism implies dualism in wages, in the sense that

- the NRC is always binding in the informal sector $\left(w_{i}^{+}(a, \bar{w})=w_{i}^{N R}(a, \bar{w})\right)$ for all a. The $N R C$ is binding in the formal sector $\left(w_{f}^{+}(a, \bar{w})=w_{f}^{N R}(a, \bar{w})\right)$ only at high skill levels, $a>\bar{w} /\left(1-\rho_{f}\right) ;$

- the highest formal offer strictly exceeds the the highest offer in the informal sector, whenever the two sectors co-exist;

- the lowest formal sector offer strictly exceeds the highest informal sector offer for at least some skill levels if employer's separation risk adjusted discount factor is sufficiently low

$$
w_{i}^{N R}\left(\bar{w} /\left(b_{E}+\left(1-b_{E}\right)\left(1-\rho_{f}\right)\right), \bar{w}\right)<\bar{w}, \Leftrightarrow b_{E}<\frac{1-\rho_{f}}{\rho_{f}} \frac{\rho_{i}}{1-\rho_{i}} .
$$


With relatively lax government enforcement in the informal sector, all informal contracts must be self-enforcing if they were to be credible. By contrast, the NRC is binding in the formal sector with stricter enforcement of the minimum wage only when wages are high, or equivalently when the skill type is high.

Contractual dualism also endogenously gives rise to wage dualism in the form of higher wages in the formal sector. This difference in wage offers is shown here to exist despite the higher job creation costs in the formal sector, and can be attributed to the difference in intensity with which government is able to enforce the minimum wage in the two sectors.

Furthermore, when the separation risk adjusted discount factor $\beta_{E}$ is sufficiently low, consistent with a heightened employers' incentive to trade off future profits in favor of immediate gains $^{18}$

$$
b_{E}<\frac{1-\rho_{f}}{\rho_{f}} \frac{\rho_{i}}{1-\rho_{i}}
$$

the range of wages for a given skill level can contain isolated segments. For example, as shown in Figure 2 which already embodies the assumption $b_{E} a<\frac{1-\rho_{f}}{\rho_{f}} \frac{\rho_{i}}{1-\rho_{i}}$, at the marginal skill level $a=\bar{w} / \theta_{f}$ where informal and formal work co-exist, formal work pays $w^{e} \in\left[\bar{w}, w_{f}^{F E}(a)\right]$, but informal work can only pay strictly less than the minimum wage $w^{e} \leq w_{i}^{+}(a, \bar{w})=w_{i}^{N R}(a, \bar{w})<$ $\bar{w}$. This is in sharp contrast to the continuous wage distributions typically implied by canonical search models (e.g. Burdett and Mortensen 1998). Instead, as we will demonstrate, our setting can imply segmented formal and informal wages, along with a wage spike at the minimum wage for workers with the same skill type. The height of such a spike in the wage distribution for any given $a$, or the economy wide distribution aggregated across all skill types, are both endogenously determined here (Section 4.2).

By contrast, employers with high $b_{E}$ put stronger emphasis on the need to retain workers and as such the self-enforcing informal wage $w_{i}^{N R}(a, \bar{w})$ will be higher. "Over-compliance" in the informal sector in this case will be a norm, in that whenever formal and informal work co-exists, there are always some informal employers paying more than the minimum wage. In what follows we will maintain the assumption that $b_{E}$ is relatively low, so that there are at least some skill levels where over-compliance is not observed in the informal sector.

\footnotetext{
${ }^{18}$ Specifically, $w_{i}^{N R}(a, \bar{w})<\bar{w}$ at $a=\bar{w} / \theta_{f}$ if and only if $\bar{w}>b_{E} \bar{w} / \theta_{f}+\left(1-b_{E}\right) q \bar{w}$. Rearranging terms yields $q<\left(1-\rho_{f}\right) / \theta_{f}$. With contractual dualism, we know that $q<\left(1-\rho_{i}\right)$. It follows that $q<\left(1-\rho_{f}\right) / \theta_{f}$ if $\left(1-\rho_{f}\right) / \theta_{f}>1-\rho_{i}$, which yields $b_{E}<\frac{1-\rho_{f}}{\rho_{f}} \frac{\rho_{i}}{1-\rho_{i}}$ as shown.
} 


\subsection{Steady State Equilibrium}

For each skill type, define a steady state equilibrium as (i) a match likelihood function $H^{*}\left(w^{e} ; a\right.$, $\bar{w}),{ }^{19}$ (ii) a set of equilibrium formal $\left(\Omega_{f}^{e}(a, \bar{w})\right)$ and informal expected wage offers $\left(\Omega_{i}^{e}(a, \bar{w})\right)$ with positive density, and (iii) levels of equilibrium unemployment $U^{*}(a, \bar{w})$, informal employment $N_{i}^{*}(a, \bar{w})$ and formal employment $N_{f}^{*}(a, \bar{w})$, such that the following equilibrium requirements are simultaneously met.

The first set of equilibrium requirements are the FEC, the NRC and the MWC, and as discussed these characterize feasible offers from a labor demand perspective. The second set incorporates labor supply response, so that no wage offer is lower than the reservation offer $w_{r}^{e}(a, \bar{w})$ : for all $w^{e} \in \Omega_{f}^{e}(a, \bar{w}), w^{e} \geq w_{r}^{e}(a, \bar{w})$, and likewise for all $w^{e} \in \Omega_{i}^{e}(a, \bar{w})$, $w^{e} \geq w_{r}^{e}(a, \bar{w})$.

A third equilibrium requirement allows both formal and informal employers the liberty to choose any wage offer in $\Omega_{f}^{e}(a)$ and $\Omega_{i}^{e}(a)$ respectively. As such, all formal and informal contracts with positive probability density yield the same expected profits:

$$
V_{i}^{o}\left(w^{e}, a, \bar{w}\right)=V_{i}^{o}\left(\hat{w}^{e}, a, \bar{w}\right)
$$

for any $w^{e}$ and $\hat{w}^{e}$ in $\Omega_{i}^{e}(a)$,

$$
V_{f}^{o}\left(w^{e}, a, \bar{w}\right)=V_{f}^{o}\left(\bar{w}^{e}, a, \bar{w}\right)
$$

for any $w^{e}$ and $\bar{w}^{e}$ in $\Omega_{f}^{e}(a)$, and finally

$$
V_{i}^{o}\left(\hat{w}^{e}, a, \bar{w}\right)=V_{f}^{o}\left(\bar{w}^{e}, a, \bar{w}\right)
$$

for any $\hat{w}^{e}$ in $\Omega_{i}^{e}(a)$ and $\bar{w}^{e}$ in $\Omega_{f}^{e}(a)$. The final requirement pins down equilibrium labor

\footnotetext{
${ }^{19}$ Note that the equilibrium distribution of offers $F^{*}\left(w^{e} ; a, \bar{w}\right)$, and the ratio of recruiting employers to unemployed workers $\lambda^{*}(a, \bar{w})=M^{*}(a, \bar{w}) / U^{*}(a, \bar{w})$ can be had once $H^{*}\left(w^{e} ; a, \bar{w}\right)$ and the lower support of $\underline{w}^{e}(a, \bar{w})=\min \left\{w^{e} \mid w^{e} \in \Omega_{f}^{e}(a, \bar{w}) \cup \Omega_{f}^{e}(a, \bar{w})\right\}$ are both determined. Specifically, from (3),$$
H^{*}\left(w^{e} ; a, \bar{w}\right)=e^{\lambda^{*}(a)\left(1-F^{*}\left(w^{e} ; a, \bar{w}\right)\right)}, \quad H^{*}\left(\underline{w}^{e} ; a, \bar{w}\right)=e^{\lambda^{*}(a)} .
$$

It follows that $F^{*}\left(w^{e} ; a, \bar{w}\right)=\left[\ln \left(H^{*}\left(w^{e} ; a, \bar{w}\right)\right)-\ln \left(H^{*}\left(\underline{w}^{e}(a) ; a, \bar{w}\right)\right)\right] / \ln \left(H^{*}\left(\underline{w}^{e}(a, \bar{w}) ; a, \bar{w}\right)\right)$, and $\lambda^{*}(a, \bar{w})=$ $-\ln \left(H^{*}\left(\underline{w}^{e}(a, \bar{w}) ; a, \bar{w}\right)\right.$.
} 
allocations. In a steady state, inflows into any state of employment must equal outflows:

$$
\begin{aligned}
p_{f}(a, \bar{w}) U^{*}(a, \bar{w}) & =\delta N_{f}^{*}(a, \bar{w}), \\
{\left[p_{i}(a, \bar{w})+p_{f}(a, \bar{w})\right] U^{*}(a, \bar{w}) } & =\delta\left[N_{i}^{*}(a, \bar{w})+N_{f}^{*}(a, \bar{w})\right], \\
\bar{N}(a) & =N_{f}^{*}(a, \bar{w})+N_{i}^{*}(a, \bar{w})+U^{*}(a, \bar{w})
\end{aligned}
$$

where $p_{f}(a, \bar{w}) \equiv \int_{w^{e} \in \Omega_{f}^{e}(a)} d H^{*}\left(w^{e} ; a, \bar{w}\right)$ refers to the fraction of unemployed workers accepting a formal sector job at any time period in a steady state, and $p_{i}(a, \bar{w}) \equiv \int_{w^{e} \in \Omega_{i}^{e}(a)} d H^{*}\left(w^{e} ; a, \bar{w}\right)$ is the fraction accepting an informal sector job. Solving (18), we obtain:

$$
\begin{gathered}
U^{*}(a, \bar{w})=\frac{\delta \bar{N}(a)}{\delta+p_{i}(a, \bar{w})+p_{f}(a, \bar{w})}, \quad N_{i}^{*}(a, \bar{w})=\frac{p_{i}(a, \bar{w}) \bar{N}(a)}{\delta+p_{i}(a, \bar{w})+p_{f}(a, \bar{w})}, \\
N_{f}^{*}(a, \bar{w})=\frac{p_{f}(a, \bar{w}) \bar{N}(a)}{\delta+p_{i}(a, \bar{w})+p_{f}(a, \bar{w})} .
\end{gathered}
$$

Thus, the higher the separation frequency $\delta$, all else equal, the larger will be the equilibrium unemployment pool. Meanwhile, informal and formal sector employment additionally depend on the fractions $p_{i}(a, \bar{w})$ and $p_{f}(a, \bar{w})$ of unemployed accepting respectively with an informal and a formal job.

\section{The No Intervention Benchmark}

Before proceeding further, a number general remarks about self-enforcing labor contracts are in order. These will help properly situate contractual dualism as a form of labor market imperfection with both distributional and efficiency consequences. In turn, the need for government policy interventions in the labor market can also be better understood.

Consider a labor market equilibrium in the absence of any policy interventions, including that of a minimum wage. If employers were able to commit ex ante to any wage offers, there will be no need for self-enforcing contracts, or the NRC. With the FEC as the only remaining constraint, it follows immediately that the value function of recruiting employers, whether formal $\left(V_{f}^{o}\left(w_{f}^{F E}, a, 0\right)\right)$ or informal $\left(V_{i}^{o}\left(w_{i}^{F E}, a, 0\right)\right)$, will be equal to zero.

Now if the NRC is a genuine concern, how will equilibrium profits, wage offers, and labor allocation be affected? Without the possibility of formalization, all contracts are informal, and all informal contracts are subject to a binding NRC, since the maximal self-enforcing wage is

$$
w_{i}^{N R}(a, 0)=b_{E} a\left(<b_{E} a+\left(1-b_{E}\right)\left(1-\rho_{i}\right) a=w_{i}^{F E}(a)\right) .
$$


which is but a fraction $b_{E}$ of the full output per worker, and strictly less than the free entry counterpart $w_{i}^{F E}(a)$.

This upper bound on wages due to the NRC can be shown to impact expected profits. Denote $\bar{V}(a, \bar{w})$ as the expected profits of employers recruiting a skill type $a$ worker. With a binding NRC instead of FEC:

$$
V_{i}^{o}\left(w_{i}^{N R}(a, 0), a, 0\right) \equiv \bar{V}(a, 0)=\frac{a-w_{i}^{N R}(a, 0)}{1-b_{E}}-\rho_{i} a=a\left(1-\rho_{i}\right)>0 .
$$

We have thus:

Proposition 4 Self-enforcing labor contracting breeds employer market power. Equilibrium expected profits $V_{i}^{o}\left(w_{i}^{N R}(a, 0), a, 0\right)$ fail to dissipate despite the absence of explicit entry barriers:

$$
V_{i}^{o}\left(w_{i}^{N R}(a, 0), a, 0\right)=a\left(1-\rho_{i}\right)>0
$$

In effect, we have here a case whereby the ability of competitive forces to bid up wages is compromised by the inability of employers to provide a credible promise of such a wage. As such, employers with an existing labor contract earn positive profits, but new entrants who may aspire to profit from hiring workers and bidding up wages cannot credibly do so without violating the NRC.

Turning now to the distribution of offers, expected profit equalization (15) - (17) along with (9) together imply that the equilibrium match likelihood strikes precisely the right balance between the cost of a higher wage offer $w^{e}$ and the benefits of a higher match likelihood $H^{*}\left(w^{e} ; a, 0\right)$, respectively for an informal employer offering $\hat{w}^{e} \in \Omega_{i}^{e}(a):^{20}$

$$
H^{*}\left(\hat{w}^{e} ; a, 0\right)=\frac{\left(1-b_{E}\right)\left(\rho_{i} a+\bar{V}(a, 0)\right)}{a-\hat{w}^{e}} .
$$

Equilibrium market power, with positive instead of zero expected profits $\bar{V}(a, 0)$ automatically gives rise to a shift in the match likelihood function consistent with lower average offers from (21):

$$
H^{*}\left(w^{e} ; a, 0\right)=\frac{\left(1-b_{E}\right)\left(\rho_{i} a+\bar{V}(a, 0)\right)}{a-w^{e}}=\frac{\left(1-b_{E}\right) a}{a-w^{e}}>\frac{\left(1-b_{E}\right) \rho_{i} a}{a-w^{e}}
$$

\footnotetext{
${ }^{20}$ To see this, note from (15) and (16) that $V_{i}^{o}\left(w^{e} ; a, 0\right)=\bar{V}(a, 0) \Leftrightarrow H^{*}\left(w^{e} ; a, 0\right)\left(a-w^{e}\right) /\left(1-b_{E}\right)-\rho_{i} a$, and $V_{f}^{o}\left(w^{e} ; a, 0\right)=\bar{V}(a, 0) \Leftrightarrow H^{*}\left(w^{e} ; a, 0\right)\left(a-w^{e}\right) /\left(1-b_{E}\right)-\rho_{f} a$. Rearranging, we obtain (21) as shown.
} 
where the latter $\left(1-b_{E}\right) \rho_{i} a /\left(a-w^{e}\right)$ would have been the equilibrium match likelihood function had expected profits $\bar{V}(\cdot)$ been driven down to zero. The effect of employer market power thus reverberates along the entire match likelihood function, consistent with a more pessimistic but nonetheless rational outlook about job prospects. It follows then from (7) that the reservation offer $w_{r}^{e}(a, 0)$ declines with employer market power. ${ }^{21}$ Indeed, the higher is the discount factor $\beta_{N}$, the larger will be this increase in the reservation offer as the weight that workers put on future earnings rather than current earnings increases.

Finally, the role of employer market power on equilibrium unemployment $U^{*}(a, 0)$ thus depends on the balance between the two aforementioned effects: (i) the shift in $H^{*}\left(w^{e} ; a, 0\right)$, and (ii) the corresponding response by workers in their choice of a reservation offer $w_{r}^{e}(a, 0)$, since inflow into the employment pool $p_{f}(a, 0)+p_{i}(a, 0)$ is equivalent to the fraction of workers receiving an acceptable offer $1-H^{*}\left(w_{r}^{e}(a, 0) ; a, 0\right):{ }^{22}$

$$
U^{*}(a, 0)=\frac{\delta \bar{N}(a)}{1+\delta-H\left(w_{r}^{e}(a, 0) ; a, 0\right)}
$$

By inspection, a lowering of the reservation expected pay $w_{r}^{e}(a, 0)$ thanks to employer market power tends to decrease unemployment as workers are discouraged from holding out too long for a high offer. But going in opposite direction, employer market power shifts downwards the match likelihood function, which directly contributes to raising $H^{*}\left(w_{r}^{e} ; a, 0\right)$, and hence unemployment at constant reservation pay $w_{r}^{e}(a, 0)$. On balance, the reservation wage effect on $w_{r}^{e}(a, 0)$ will be weak if the discount factor $\beta_{N}$ is relatively low from (7). ${ }^{23}$

Summarizing, a low wage, high unemployment equilibrium with informal employer market power emerges simply as a consequence of the need for self-enforcing labor contracts. In equilibrium, the NRC effectively deters the entry of new offers with high wages, and raises unemployment unless workers respond by making a huge adjustment in the reservation offer

\footnotetext{
${ }^{21}$ See Appendix A for a proof of this claim.

${ }^{22}$ This follows since $\Omega_{i}^{e}(a, 0) \cup \Omega_{f}^{e}(a, 0)=\Omega_{i}^{e}(a, 0)=\left[w_{r}^{e}(a, 0), w_{i}^{N R}(a, 0)\right]$ in the absence of a minimum wage, and hence a formal sector. Specifically, since $\bar{w}=0, w_{i}^{-}(a, 0)=w_{f}^{-}(a, 0)=0$ from the MWC. At any unemployment income $\bar{u} \geq 0$, it must be the case that $w_{r}^{e}(a, 0) \geq w_{i}^{-}(a, 0)=w_{f}^{-}(a, 0)=0$. Together with the earlier observation that there is no formal employment, it follows therefore that the lower support of $\Omega_{i}^{e}(a, 0)=\left[w_{r}^{e}(a, 0), w_{i}^{N R}(a, 0)\right]$.

${ }^{23}$ To see this, recall that

$$
w_{r}^{e}(a, 0)=\bar{u}+\frac{\beta_{N}}{1-b_{N}} \int_{w_{r}^{e}(a, 0)}^{\infty}\left(x-w_{r}^{e}(a, 0)\right) d H(x ; a, 0) .
$$
}

The role of $H^{*}\left(w^{e} ; a, 0\right)$ on the reservation offer depends critically on the size of $\beta_{N}$. 
$w_{r}^{e}(a, 0)$. In terms of distribution, the need for self-enforcing contracts shifts income distribution in favor of employers with an existing worker as expected profits turn positive. In terms of efficiency, the need for self-enforcing contracts lowers total output as unemployment increases.

With these in mind, policy measures that aim at improving upon this no intervention baseline can be targeted towards allaying distributional inequities between employers and workers, towards improving efficiency, or as the case may be, both. In the next section, we examine a minimum wage, and thus the possibility of formalization, as a potential candidate. Our goal is to explore the role of a minimum wage on (i) expected employer profits, which we take as a gauge of the extent of employer market power despite the absence of explicit barriers, (ii) the equilibrium distribution of offers, from which the equilibrium wage distribution readily follows, and (iii) the equilibrium allocation of laborers as informal workers, formal workers, and unemployed workers.

\section{Minimum Wage Policy}

\subsection{Market Power and the Minimum Wage}

To better appreciate the role of a minimum wage on employer market power, we reorganize the information presented in Figure 2 to highlight how successively higher levels of the minimum wages impact formal and informal labor demand as given by the joint application of the MWC, the FEC, and the NRC in Figure 3.

The bold lines mark four areas of interest. The area marked $A_{f}^{N R}-$ an area of low minimum wages at high skill levels - gives all combinations of $\bar{w}$ and $a$ such that the informal and formal labor demand co-exists $\left(a \geq \bar{w} /\left(1-\rho_{f}\right)\right)$. With the government enforced minimum wage still relatively low, the NRC in the formal sector is binding, although $w_{f}^{N R}(a, \bar{w})=$ $b_{E} a+\left(1-b_{E}\right) \max \{\bar{w}, a\}$ already exceeds the no minimum wage baseline at $b_{E} a$. The area marked $A_{f}^{F E}$ covers higher levels of minimum wage. Government enforcement of this higher wage now improves the credibility of formal contracts so much so that the NRC no longer binds, and the FEC takes its place $a \in\left[\bar{w} /\left[b_{E}+\left(1-b_{E}\right)\left(1-\rho_{f}\right)\right], \bar{w} /\left(1-\rho_{f}\right)\right]$. Further raising this minimum wage to $A_{i}^{N R}$ results in a complete exodus of employers out of the formal sector in favor of informality, where enforcement of the high minimum wage is relatively lax $\left(a \in\left[\bar{w} / \theta_{f}\right), \bar{w}\right)$. With contractual dualism, the NRC is binding for all such informal 
employers. ${ }^{24}$

As the relative importance of the MWC, FEC, and NRC varies as $\bar{w}$ rises and traverses from one area to the next, the maximal offer $w^{+}(a, \bar{w})$ consistent with the MWC, FEC, and the NRC changes endogenously as well from (14). Naturally, therefore, employer profits changes with $\bar{w}$ as well. As with (20) in Section 3.1, let $\bar{V}(a, \bar{w})$ denote the value function of the employer with the highest offer, where

$$
\bar{V}(a, \bar{w})=V_{i}^{o}\left(w^{+}(a, \bar{w}), a, \bar{w}\right)=\frac{a-w^{+}(a, \bar{w})}{1-b_{E}}-\rho_{i} a
$$

if $w^{+}(a, \bar{w})=w_{i}^{+}(a, \bar{w})$ is offered in the informal sector. Otherwise,

$$
\bar{V}(a, \bar{w})=V_{f}^{o}\left(w^{+}(a, \bar{w}), a, \bar{w}\right)=\frac{a-w^{+}(a, \bar{w})}{1-b_{E}}-\rho_{f} a
$$

Of course, in equilibrium, $\bar{V}(a, \bar{w})$ is equal to expected profit of all employers with wage offers supported by $H^{*}\left(w^{e} ; a, \bar{w}\right)$ from (15) - (17). We have:

Proposition 5 With contractual dualism,

- Expected profit $\bar{V}(a, \bar{w})=a-\bar{w}-\rho_{f} a$ is strictly positive for all $(a, \bar{w}) \in A_{f}^{N R}$ despite no explicit barriers to entry. A further increase in $\bar{w}$ lowers $\bar{V}(a, \bar{w})$

- Expected profit $\bar{V}(a, \bar{w})$ is at zero for all $(a, \bar{w}) \in A_{f}^{F E}$. A further increase in $\bar{w}$ has no local effect on $\bar{V}(a, \bar{w})$.

- Transitioning from $A_{f}^{F E}$ to $A_{i}^{N R}$, there is a discrete upward jump in expected profits at $\bar{w}=a / \theta_{f}$ as all formal employers become informalized at $w^{e}>a / \theta_{f}$. A further increase in $\bar{w}$ will decrease expected profit $\bar{V}(a, \bar{w})=a-q \bar{w}-\rho_{i}$ a if and only if $q>0$.

The relationship between employer profits and the minimum wage is thus non-monotonic and u-shaped. As shown in Figures 4a and 4b, at low levels of $\bar{w}$, raising $\bar{w}$ unleashes competitive forces previously held back by the NRC, and helps keep equilibrium employer market power in check by enabling formal employers to make credible high wage offers. The smallest minimum wage that completely eliminates employer market power is $\bar{w}=a\left(1-\rho_{f}\right)$, while the smallest

\footnotetext{
${ }^{24}$ Minimum wages in the remaining area are strictly higher than $a$ and are thus outside of the feasible range $(\bar{u}, a)=(0, a)$
} 
minimum wage that gives rise full informality is $\bar{w}=\theta_{f} a$. Thereafter, employer profits experience a discrete improvement due to lax enforcement of the minimum wage in the informal sector. The ability of the minimum wage to curb employer profits after this point will depend critically on the size of $q$. Clearly, further raising the minimum wage beyond $a$ will produce no further results either in terms of curbing employer market power, or raising equilibrium wage offerings.

These results have direct implications on the equilibrium match likelihoods facing unemployed workers, and by implication the equilibrium wage distribution among employed workers as well. ${ }^{25}$ We turn to these next.

\subsection{The Wage Distribution}

From the equilibrium equal profit requirement, the match likelihood function is given as in (21) as

$$
H^{*}\left(\hat{w}^{e} ; a, \bar{w}\right)=\frac{\left(1-b_{E}\right)\left(\rho_{i} a+\bar{V}(a, \bar{w})\right)}{a-\hat{w}^{e}}, H^{*}\left(\tilde{w}^{e} ; a, \bar{w}\right)=\frac{\left(1-b_{E}\right)\left(\rho_{f} a+\bar{V}(a, \bar{w})\right)}{a-\tilde{w}^{e}}
$$

respectively for $\hat{w}^{e} \in \Omega_{i}^{e}(a, \bar{w})$, and $\tilde{w}^{e} \in \Omega_{f}^{e}(a, \bar{w})$. This indicates clearly that rising equilibrium employer profits $\bar{V}(a, \bar{w})$ are associated with backward shifts in the entire match likelihood function, consistent with lower average wage matches. It follows immediately from Proposition 5 that the minimum wage, via its impact on expected employer profits $\bar{V}(a, \bar{w})$, can have interesting and non-monotonic impact on the match likelihood function.

Our task here involves tracking both the height and shape of the match likelihood function as the minimum wage changes. To do so we first note two observations. First, recall from Figure 2 that the size of the minimum wage determines whether formal and informal demand

\footnotetext{
${ }^{25}$ Information on $H^{*}\left(w^{e} ; a, \bar{w}\right)$ has direct implications on the realized expected wage distribution in the steady state. Let $G^{*}\left(w^{e}, a, \bar{w}\right)$ denote the expected wage distribution among employed workers. In a steady state, outflow of workers from the pool of employed workers earning less than $w^{e}$ equals inflow, and thus:
}

$$
\delta G^{*}\left(w^{e}, a, \bar{w}\right)\left(1-U^{*}(a, \bar{w})\right)=\left[H^{*}\left(w^{e} ; a, \bar{w}\right)-\left[1-p_{f}(a, \bar{w})-p_{i}(a, \bar{w})\right)\right] U^{*}(a, \bar{w})
$$

where $p_{f}=\int_{w^{e} \in \Omega_{f}^{e}(a, \bar{w})} d H^{*}\left(w^{e} ; a, \bar{w}\right)$ and $p_{i}=\int_{w^{e} \in \Omega_{f}^{e}(a, \bar{w})} d H^{*}\left(w^{e} ; a, \bar{w}\right)$, to recall, are the fraction of unemployed workers receiving a job offer in the two sectors. Rearranging, we have:

$$
G^{*}\left(w^{e}, a, \bar{w}\right)=\frac{p_{f}(a, \bar{w})+p_{i}(a, \bar{w})+H^{*}\left(w^{e} ; a, \bar{w}\right)-1}{p_{f}(a, \bar{w})+p_{i}(a, \bar{w})} .
$$


co-exist $\left(A_{f}^{N R}\right.$ and $A_{f}^{F E}$ ), or where only informal employers remain $\left(A_{i}^{N R}\right)$. Second, with coexistence, there is furthermore the question of whether there exist informal employers that over-comply with the minimum wage legislation. This occurs when the maximal self-enforcing informal wage exceeds the minimum wage, or

$$
w_{i}^{+}(a, \bar{w})=w_{i}^{N R}(a, \bar{w})=b_{E} a+\left(1-b_{E}\right) q\{\bar{w}, a\} \geq \bar{w}
$$

or equivalently

$$
\bar{w} \leq \frac{b_{E} a}{1-\left(1-b_{E}\right) q}(<a) .
$$

Henceforth we assume that the discount factor $b_{E}$ is sufficiently small, so that $b_{E} a /(1-(1-$ $\left.\left.b_{E}\right) q\right)<1-\rho_{f}$ as shown via the dotted line in Figure 3. It follows that for all $\bar{w} \leq b_{E} a /(1-(1-$ $\left.b_{E}\right) q$ ), informal demand is strong enough to support over-complying employers. By contrast, for all $\bar{w}>b_{E} a /\left(1-\left(1-b_{E}\right) q\right)$, the highest informal sector offer is lower than the lowest formal sector offer at $\bar{w}$. For all such minimum wage and skill type pairings, the match likelihood functions exhibits segmented formal and informal wages, along with a spike at the minimum wage.

The match likelihood $H^{*}\left(w^{e} ; a, \bar{w}\right)$ associated with each of the four areas $A_{f}^{N R}, A_{f}^{F E}$, and $A_{i}^{N R}$ can now be easily obtained. Starting with $\bar{w}<\frac{b_{E} a}{1-\left(1-b_{E}\right) q}$, where the NRC is binding in the formal sector, we have from Proposition 5 that expected profits is $\bar{V}(a, \bar{w})=a-\bar{w}-\rho_{f} a$. As in (21), expected profit equalization implies the following equilibrium match likelihood function: ${ }^{26}$ $H^{*}\left(w^{e} ; a, \bar{w}\right)= \begin{cases}H_{i}^{*}\left(w^{e} ; a, \bar{w}\right)=\frac{\left(1-b_{E}\right)\left(a-\bar{w}-\left(\rho_{f}-\rho_{i}\right) a\right)}{a-w^{e}}, & w^{e} \leq w_{i}^{N R}(a, \bar{w}) \\ H_{f}^{*}\left(w^{e} ; a, \bar{w}\right)=\frac{\left(1-b_{E}\right)(a-\bar{w})}{a-w^{e}}, & w^{e} \in\left(w_{i}^{N R}(a, \bar{w}), w_{f}^{N R}(a, \bar{w})\right] .\end{cases}$ The two segments respectively give the match likelihoods facing informal sector workers at low wages $w^{e} \leq w_{i}^{N R}(a, \bar{w})$, and formal sector workers at wages higher than $w_{i}^{N R}(a, \bar{w})$ (Figures 2 and 3). From Proposition 5, a minimum wage hike $\bar{w}$ in this range decreases employer expected profits. Accordingly, the same minimum wage hike gives rise to a first order stochastically dominating (rightward) shift in the match likelihood function consistent with higher wage offer expectations.

\footnotetext{
${ }^{26}$ With higher job creation cost in the formal sector, an offer generates higher informal profits than formal profits so long as $w^{e}$ is feasible, or $w^{e} \leq w_{i}^{N R}(a, \bar{w})$ since $V_{i}^{o}\left(w^{e}, a, \bar{w}\right)=H^{*}\left(w^{e}, a, \bar{w}\right) V_{i}\left(w^{e}, a\right)-\rho_{i} a<$ $H^{*}\left(w^{e} ; a, \bar{w}\right) V_{f}\left(w^{e}, a\right)-\rho_{f} a=V_{f}^{o}\left(w^{e}, a, \bar{w}\right)$. Thus, all employers offering less than $w_{i}^{N R}(a, \bar{w})$ are informal employers.
} 
Raising $\bar{w}$, so $a\left(1-\rho_{f}\right)>\bar{w}>\frac{b_{E} a}{1-\left(1-b_{E}\right) q}$, the equilibrium match likelihood function is

$$
H^{*}\left(w^{e} ; a, \bar{w}\right)= \begin{cases}H_{i}^{*}\left(w^{e} ; a, \bar{w}\right)=\frac{\left(1-b_{E}\right)\left(a-\bar{w}-\left(\rho_{f}-\rho_{i}\right) a\right)}{a-w^{e}}, & w^{e} \leq w_{i}^{N R}(a, \bar{w}) \\ H_{o}^{*}\left(w^{e} ; a, \bar{w}\right)=\frac{a-\bar{w}-\left(\rho_{f}-\rho_{i}\right) a}{a-q \bar{w}}, & w^{e} \in\left(w_{i}^{N R}(a, \bar{w}), \bar{w}\right) \\ H_{f}^{*}\left(w^{e} ; a, \bar{w}\right)=\frac{\left(1-b_{E}\right)(a-\bar{w})}{a-w^{e}}, & w^{e} \in\left[\bar{w}, w_{f}^{N R}(a, \bar{w})\right] .\end{cases}
$$

The intermediate segment $H_{o}^{*}\left(w^{e} ; a, \bar{w}\right)=H_{i}^{*}\left(w_{i}^{N R}(a, \bar{w}) ; a, \bar{w}\right)$ for $w^{e} \in\left(w_{i}^{N R}(a, \bar{w}), \bar{w}\right)$ represents the range of wages too high for informal employers, but too low for formal employers with a mandated minimum wage. The height of the minimum wage spike is given by $H_{f}^{*}(\bar{w} ; a, \bar{w})-H_{i}^{*}\left(w_{i}^{N R}(a, \bar{w}) ; a, \bar{w}\right)=1-b_{E}-\left(a-\bar{w}-\left(\rho_{f}-\rho_{i}\right) a\right) /(a-q \bar{w})$. Table 1 summarizes the rest of the match likelihood functions obtained in analogous fashion. Proposition 6 below summarizes the match likelihood impact of the minimum wage, which reflects directly the expected profit impact of a minimum wage already seen in Proposition 5:

Proposition 6 With contractual dualism, and a sufficiently small discount factor $b_{E}$ such that $b_{E} a /\left(1-\left(1-b_{E}\right) q\right)<1-\rho_{f}$

- For $(a, \bar{w}) \in A_{f}^{N R}$ and $\bar{w}$ sufficiently small $\left(\leq b_{E} a /\left[1-\left(1-b_{E}\right) a\right]\right.$, some informal employers over-comply $\left(w_{i}^{N R}(a, \bar{w})>\bar{w}\right)$. An increase in $\bar{w}$ shifts $H^{*}\left(w^{e} ; a, \bar{w}\right)$ to the right.

- Next, for $(a, \bar{w}) \in A_{f}^{N R}$ and $\bar{w} \in\left[b_{E} a /\left[1-\left(1-b_{E}\right) a\right], a\left(1-\rho_{f}\right), H^{*}\left(w^{e} ; a, \bar{w}\right)\right.$ exhibits a spike at $\bar{w}$. An increase in $\bar{w}$ likewise shifts the match likelihood function $H^{*}\left(w^{e} ; a, \bar{w}\right)$ to the right.

- Now for all $(a, \bar{w}) \in A_{f}^{F E}, H^{*}\left(w^{e} ; a, \bar{w}\right)$ exhibits a spike at $\bar{w}$. An increase in $\bar{w}$ gives rise to a single crossing shift of $H^{*}\left(w^{e} ; a, \bar{w}\right)$ with crossing from above if and only if $q>0$, and a rightward shift of $H^{*}\left(w^{e} ; a, \bar{w}\right)$ otherwise.

- Transitioning from $A_{f}^{F E}$ to $A_{i}^{N R}$ there is a discrete shift in the distribution leftwards as all formal employers become informalized. Further increases in $\bar{w}$ will shift $H^{*}\left(w^{e} ; a, \bar{w}\right)$ to the right if and only if $q>0$, and $H^{*}\left(w^{e} ; a, \bar{w}\right)$ is invariant to $\bar{w}$ otherwise.

Figures 5 and 6 summarize these observations and illustrate the equilibrium match likelihood functions for successively higher levels of the minimum wage, given $a$, and $q>0$ in Figure 
5, and $q=0$ in Figure 6. As shown, at low levels of the minimum wage (Figure 5a and 6a) $\left((\bar{w}, a) \in A_{f}^{N R}\right)$, the formal NRC and the informal NRC are both binding. Here, formal and informal job offers co-exist, and there is over-compliance in the informal sector. An increase in the minimum wage lowers expected employer profits, and shifts the match likelihood function to the right from $H^{o}$ where $\bar{w}=0$, to $H^{1}$ and then to $H^{2}$ for successively higher levels of $\bar{w}>0$.

Higher minimum wages eventually generate a spike at the $\bar{w}$ for $(\bar{w}, a) \in A_{f}^{F E}$. An increase in the minimum wage now shifts the formal wage associated with the spike, in such a way that the match likelihood $H^{*}(\bar{w} ; a, \bar{w})$ evaluated at the new minimum wage is exactly the same as before the minimum wage hike, consistent with the FEC (Figures 5b and 6b). Meanwhile, a higher minimum wage raises the credibility of higher wage offers in the informal sector so long as $q>0$. This raises the maximal informal offer as well. The result is a singlecrossing shift in $H^{*}\left(w^{e} ; a, \bar{w}\right)$ as stated in Proposition 6 , and shown in Figures $5 \mathrm{~b}$ and $6 \mathrm{~b}$ via the shift from $H^{3}$ to $H^{4}$.

Still higher levels of the minimum wage yields a discrete transition to a match likelihood function with informal offers only. With relatively lax enforcement, employers preserve their market power here, and the ability of further increases in the minimum wage in raising wage prospects in the informal sector depends critically on $q$. In Figures $5 \mathrm{c}$ and $6 \mathrm{c}$, we illustrate the two match likelihood functions $\left(H^{4}\right.$ and $\left.H^{5}\right)$ respectively before and after the transition evaluated at the marginal minimum wage $\bar{w}=a \theta_{f}$. Thereafter, further increases in the minimum wage with a strictly positive enforcement likelihood in the informal sector $q$ gives rise to a shift from $H^{5}$ to $H^{6}$ in Figure 5c. Otherwise, with $q=0, H^{*}(\cdot)$ is invariant to further increases in the minimum wage as in Figure 6c.

In sum, the minimum wage can have impact throughout the entire match likelihood function both above and below the minimum wage in very nuanced ways. To complete our specification of the match likelihood function, a characterization of the equilibrium range of offers with positive density $\left(\Omega_{f}^{e}(a, \bar{w})\right.$ and $\left.\Omega_{i}^{e}(a, \bar{w})\right)$ is critical. Doing so requires incorporating supply side considerations, which will also provide the labor allocation implications of a minimum wage. 


\subsection{Employment, Unemployment and the Optimal Minimum Wage}

Recall that in a steady state equilibrium,

$$
\begin{gathered}
U^{*}(a, \bar{w})=\frac{\delta \bar{N}(a)}{\delta+p_{i}(a, \bar{w})+p_{f}(a, \bar{w})}, \quad N_{i}^{*}(a, \bar{w})=\frac{p_{i}(a, \bar{w}) \bar{N}(a)}{\delta+p_{i}(a, \bar{w})+p_{f}(a, \bar{w})}, \\
N_{f}^{*}(a, \bar{w})=\frac{p_{f}(a, \bar{w}) \bar{N}(a)}{\delta+p_{i}(a, \bar{w})+p_{f}(a, \bar{w})} .
\end{gathered}
$$

These steady state labor allocations are determined as soon as the share of unemployed workers with an informal match $p_{i}=\int_{w^{e} \in \Omega_{i}^{e}} d H^{*}\left(w^{e} ; a, \bar{w}\right)$, and a formal match $p_{f}=\int_{w^{e} \in \Omega_{f}^{e}} d H^{*}\left(w^{e} ; a, \bar{w}\right)$ are determined. Thus, apart from its impact on the match likelihood $H^{*}\left(w^{e} ; a, \bar{w}\right)$ discussed in Proposition 6, a minimum wage can impact equilibrium labor allocation by changing the equilibrium range of wage offers with positive density $\Omega_{i}^{e}$ and $\Omega_{f}^{e}$ as well.

To this end, the upper support of $\Omega_{f}^{e}$ and $\Omega_{i}^{e}$ have already been discussed, and are bounded above by $w_{i}^{+}(a, \bar{w})$ and $w_{f}^{+}(a, \bar{w})$ depending on the juxtaposition of the NRC, and the FEC. This leaves the lower support associated with $\Omega_{i}^{e}(a, \bar{w})$ and $\Omega_{f}^{e}(a, \bar{w})$, respectively $w_{i}^{-}(a, \bar{w})$ and $w_{f}^{-}(a, \bar{w})$. Combining the MWC on the informal demand side, and $w^{e} \geq w_{r}^{e}(a, \bar{w})$ as the labor supply constraint, the minimum offer in the informal sector $w_{i}^{-}(a, \bar{w})$ is

$$
w_{i}^{-}(a, \bar{w})=\min \left\{w^{e} \mid w^{e} \in \Omega_{i}^{e}(a, \bar{w})\right\}=\max \left\{q \bar{w}, w_{r}^{e}(a, \bar{w}\}\right\}
$$

where the lower support of informal wages is given either by the government enforced $q \min \{\bar{w}, a\}$, or the reservation offer $w_{r}^{e}(a, \bar{w})$, whichever is smaller.

In the formal sector, $w_{f}^{-}(a, \bar{w})$ depends on the juxtaposition of the MWC on the formal demand side $\left(w^{e} \geq \bar{w}\right),{ }^{27}$ the possibility of over-compliance in the informal sector $\left(w_{i}^{+}(a, \bar{w}) \geq\right.$ $\bar{w}$ ) already discussed (when $b_{E} a /\left[1+\left(1-b_{E}\right) q\right] \geq \bar{w}$ ), as well as the labor supply constraint $w^{e} \geq w_{r}^{e}(a, \bar{w})$. Thus,

$$
w_{f}^{+}(a, \bar{w})=\max \left\{\bar{w}, w_{i}^{N R}(a, \bar{w}), w_{r}^{e}(a, \bar{w})\right\} .
$$

It follows that only formal employment prevails in equilibrium if $w_{f}^{+}(a, \bar{w})=w_{r}^{e}(a, \bar{w})$, or when workers value highly the returns from potentially a more prolonged wait for a formal offer. Clearly, the higher $\beta_{N}$ is, the more likely this will be the case. We are now in a position to

\footnotetext{
${ }^{27}$ Recall from our discussion of Proposition 5 and Figure 2 that only informal employers can sustain employment when minimum wages higher than $a$. Thus, the MWC on the formal demand side is $w^{e} \geq \min \{\bar{w}, a\}=\bar{w}$ as shown.
} 
address the labor allocation consequences of a minimum wage. We begin with this preliminary observation:

Proposition 7 For all $(a, \bar{w}) \in A_{i}^{N R}(\bar{w})$, there is no formal employment, while the range of informal wage offers with strictly positive density is

$$
\Omega_{i}^{e}(a, \bar{w})=\left[\max \left\{q \bar{w}, w_{r}^{e}(a, \bar{w}\}\right\}, w_{i}^{N R}(a, \bar{w})\right] .
$$

Otherwise for all $(a, \bar{w}) \in A_{f}^{F E} \cup A_{f}^{N R}$, formal and informal employment co-exist, and the range of formal wage offers with strictly positive density is

$$
\Omega_{f}^{e}(a, \bar{w})=\left[\max \left\{\bar{w}, w_{i}^{N R}(a, \bar{w})\right\}, w_{f}^{+}(a, \bar{w})\right] .
$$

if $\beta_{N}$ is sufficiently small.

Table 2 follows Proposition 7 and assumes that $\beta_{N}$ is sufficiently small, so as to allow us to focus on situations where both formal and informal employment are prevalent. Equilibrium labor allocations associated with each of the subsets $A_{i}^{N R}, A_{i}^{F E}$ and $A_{f}^{N R}$ are displayed and the comparative statics of a minimum wage is summarized.

Right away, it is not difficult to see that a minimum wage introduces opposing forces that can either raise or decrease unemployment. In particular, from Proposition 6, a higher minimum wage leads to higher wage expectations. This raises the lower support $w_{i}^{-}(a, \bar{w})$, and thus unemployment through $H^{*}\left(w_{i}^{-}(a, \bar{w}) ; a, \bar{w}\right)$ as workers are encouraged to wait for a better job. The only exception is for $a \in A_{f}^{F E}$, where the credibility is enhanced for both higher paying formal job offers and lower paying informal job offers for strictly positive $q>0$. Going in opposite direction, an increase in the minimum wage raises the credibility of high offers, decreasing unemployment along the way as it shifts $H^{*}\left(w^{e} ; a, \bar{w}\right)$ to the right.

In view of these observations, Table 2 summarizes the comparative statics of a minimum wage hike in all four subsets, capturing unemployment, informal employment, formal employment, as well as the number of workers paid at exactly the minimum wage, $\bar{N}_{f}(a, \bar{w})$. This is done based on the following set of assumptions. First, workers' discount rate $\beta_{E}$ is not too high, so that informal and formal employment co-exist, and also so that the impact of future wage expectations on current reservation offer is not too high (equation 7). Second, the enforcement intensity of the minimum wage in the informal sector is sufficiently small consistent 
with contractual dualism. This guarantees that the credibility effect of a minimum wage hike is more focussed on formal labor contracts. Summarizing the results presented in Table $2:{ }^{28}$

Proposition 8 If $\beta_{E}$ and $\beta_{N}$ are not too high, and if $q$ is likewise sufficiently small,

- there is a u-shaped relationship between equilibrium unemployment $U^{*}(a, \bar{w})$ and the minimum wage. The unemployment minimizing minimum wage coincides with the smallest minimum wage that eliminates employer market power, a $\left(1-\rho_{f}\right)$.

- there is a $U$-shaped relationship between equilibrium informal employment $N_{i}^{*}(a, \bar{w})$ and the minimum wage.

- equilibrium total formal employment $N_{f}^{*}(a, \bar{w})$, and formal employment at the minimum wage $N_{f}^{*}(a, \bar{w})$ first rises, and eventually falls with successively higher levels of the minimum wage.

The driving force behind Proposition 8 highlights once again the dual role of a minimum wage that is already evident in our discussion of Proposition 5. Government enforcement of the minimum wage relaxes the NRC, and by so doing it presents a partial solution to the low wage, high unemployment problem inherent in labor contracting with a self-enforcing constraint. But raising the minimum wage too high runs the risk of encouraging informalization, where lax enforcement once again accommodates employer market power, and a return to a low wagehigh unemployment equilibrium.

In summary, the model we proposed generates a number of predictions that are in line with the salient features of the informal labor market outlined in the introduction: the coexistence of formal and informal work, wage dualism and in particular wage spikes along the distribution depending on the minimum wage, co-movements between the informal wage and the minimum wage depending on the level of enforcement, and finally a very nuanced set of comparative statics response related to the minimum wage impact on labor allocations.

The model also generates sharp implications concerning the choice of a minimum wage. From the discussion following Proposition 5 and also from Proposition 8, the minimum wage

\footnotetext{
${ }^{28}$ See Appendix B for a proof of this proposition.
} 
that minimizes employer expected profits, while maximizing total informal and formal employment follows a remarkably simple and intuitive formula: $\bar{w}^{*} \equiv a\left(1-\rho_{f}\right)$. In the absence of formal sector job creation costs, the minimum wage $\bar{w}^{*}=a$ coincides with the Stigler (1946) prescription, where the employment maximizing minimum wage is simply the marginal value product of labor in an otherwise competitive labor market. Thus, the higher the productivity, the higher the minimum wage should be. But with a positive cost of formalization, $\bar{w}^{*}$ rules out full marginal productivity pricing. Being based both on productivity and job creation costs, implicit in this formula is the implication that $\bar{w}^{*}$ need not even meet the poverty line. To the best of our knowledge, this paper is the first that a provides a link between the cost of formalization $\rho_{f}$, and the formulation of an optimal minimum wage that eliminates employer market power, and maximizes employment.

To establish a raw gauge on the importance of entry cost in the determination of the optimal minimum wage, consider for example data collected regarding the regulation cost of entry of start-up firms in 85 developed and developing countries from Djankov et. al (2002). The data cover the number of procedures, official time, and official cost that a start-up must bear before it can operate legally. The direct and time cost of entry is expressed as a fraction of GDP per capita in 1999 - a proxy of our $\rho_{f}$. As reported in Djankov et. al (2002), these entry costs are indeed substantial in many countries, with an average $\rho_{f}$ of 0.66 and median $\rho_{f}$ of 0.40. Thus, the optimal minimum wage that minimizes unemployment is indeed substantially smaller than the Stiglerian prediction.

\section{Conclusion}

This paper models the confluence of three strands of the literature on formality and informality in developing countries - the degree of competition in the labor market, the ease of labor contract enforcement, and government regulation of wages. We present an equilibrium where workers and firms sign contracts that will not be reneged upon; and firms can choose between the formal sector, where minimum wage regulations are strongly enforced, and the informal sector, where they are only weakly enforced. We show that this model is able to account jointly for a number of stylized facts on wages and labor in developing countries. We demonstrate conditions under which employer power is greater in the informal sector because 
of non-enforceable contracts. In the formal sector enforcement of minimum wage regulation indirectly provides a partial commitment technology, thereby improving efficiency and equity in some ranges. Finally, we derive the optimal minimum wage taking into account the full equilibrium repercussions in both sectors.

To conclude, let us emphasize again that two conventional characterizations of the informal sector - that it is more competitive and that it has greater difficulty of contract enforcement - are incompatible with each other. Greater difficulty of contract enforcement in our model leads to greater employer power in the informal sector. Paradoxical as it may seem, government regulation mitigates the potential for employer power by providing a technology of third party enforcement, whose effects spill over to the informal sector and can lead to greater efficiency and greater equity in the economy as a whole. 
Table 1. The Minimum Wage and the Match Likelihood Function

$$
\begin{aligned}
& (a, \bar{w}) \in A_{f}^{N R} \text { and } \bar{w} \leq b_{E} a /\left(1-\left(1-b_{E}\right) q\right) \\
& H^{*}\left(w^{e} ; a, \bar{w}\right)=H_{i}^{*}\left(w^{e} ; a, \bar{w}\right)=\left(1-b_{E}\right)\left(a-\bar{w}-\left(\rho_{f}-\rho_{i}\right) a\right) /\left(a-w^{e}\right), \quad w^{e} \leq w_{i}^{N R} \\
& H_{f}^{*}\left(w^{e} ; a, \bar{w}\right)=\left(1-b_{E}\right)(a-\bar{w}) /\left(a-w^{e}\right), \quad w^{e} \in\left(w_{i}^{N R}, w_{f}^{N R}\right] . \\
& (a, \bar{w}) \in A_{f}^{N R} \text { and } \bar{w}>b_{E} a /\left(1-\left(1-b_{E}\right) q\right) \\
& H^{*}\left(w^{e} ; a, \bar{w}\right)=H_{i}^{*}\left(w^{e} ; a, \bar{w}\right)=\left(1-b_{E}\right)\left(a-\bar{w}-\left(\rho_{f}-\rho_{i}\right) a\right) /\left(a-w^{e}\right), \quad w^{e} \leq w_{i}^{N R} \\
& H_{o}^{*}\left(w^{e} ; a, \bar{w}\right)=\left(a-\bar{w}-\left(\rho_{f}-\rho_{i}\right) a\right) /(a-q \bar{w}), \quad w^{e} \in\left(w_{i}^{N R}, \bar{w}\right) \\
& H_{f}^{*}\left(w^{e} ; a, \bar{w}\right)=\left(1-b_{E}\right)(a-\bar{w}) /\left(a-w^{e}\right), \quad w^{e} \in\left[\bar{w}, w_{f}^{N R}\right] . \\
& (a, \bar{w}) \in A_{f}^{F E} \\
& H^{*}\left(w^{e} ; a, \bar{w}\right)=H_{i}^{*}\left(w^{e} ; a, \bar{w}\right)=\left(1-b_{E}\right) \rho_{i} a /\left(a-w^{e}\right), \quad w^{e} \leq w_{i}^{N R} \\
& H_{o}^{*}\left(w^{e} ; a, \bar{w}\right)=\rho_{i} a /(a-q \bar{w}), \quad w^{e} \in\left(w_{i}^{N R}, \bar{w}\right) \\
& H_{f}^{*}\left(w^{e} ; a, \bar{w}\right)=\left(1-b_{E}\right) \rho_{f} a /\left(a-w^{e}\right), \quad w^{e} \in\left[\bar{w}, w_{f}^{F E}\right] . \\
& (a, \bar{w}) \in A_{i}^{N R}
\end{aligned}
$$

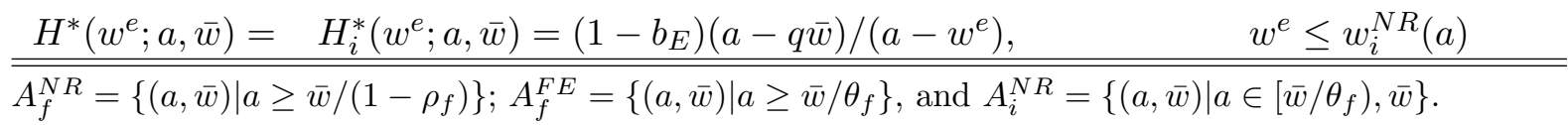


Table 2. Expected Profits, Equilibrium Labor Allocation and the Minimum Wage ${ }^{29}$

\begin{tabular}{c|c|c|c|c}
\hline & $\begin{array}{c}\text { Coexistence of } \\
\text { Informal and } \\
\text { Employment }\end{array}$ & $\begin{array}{r}\text { Transition from } \\
\text { Coexistence to } \\
\text { Informal Only }\end{array}$ & $\begin{array}{r}\text { Informal } \\
\text { Employment } \\
\text { Only }\end{array}$ \\
\cline { 2 - 5 } & $\begin{array}{c}(a, \bar{w}) \in A_{f}^{N R} \\
\bar{w}<\left(1-\rho_{f}\right) a\end{array}$ & $\begin{array}{c}\left.(a, \bar{w}) \in A_{f}^{F E}\right) \\
\left.\bar{w}\left(1-\rho_{f}\right) a, \theta_{f} a\right)\end{array}$ & $\bar{w}=\theta_{f} a$ & $\begin{array}{c}(a, \bar{w}) \in A_{i}^{N R} \\
\bar{w} \in\left(\theta_{f} a, a\right]\end{array}$ \\
\hline $\bar{V}(a, \bar{w})$ & $<0$ & no change & $\begin{array}{r}\lim _{\epsilon \rightarrow 0}\left[\bar{V}\left(a, \theta_{f} a+\epsilon\right)\right. \\
\left.-\bar{V}\left(a, \theta_{f} a-\epsilon\right)\right]>0\end{array}$ & $\begin{array}{c}<0 \text { if } q>0 \\
\text { no change if } q=0\end{array}$ \\
\hline$U^{*}(a, \bar{w})$ & $<0$ & $>0$ & $\begin{array}{r}\lim _{\epsilon \rightarrow 0}\left[U^{*}\left(a, \theta_{f} a+\epsilon\right)\right. \\
\left.-U^{*}\left(a, \theta_{f} a-\epsilon\right)\right]>0\end{array}$ & $\begin{array}{c}<0 \text { or no change if } q>0 \\
\text { no change if } q=0\end{array}$ \\
\hline$N_{i}^{*}(a, \bar{w})$ & $<0$ & $>0$ & $\begin{array}{r}\lim _{\epsilon \rightarrow 0}\left[N_{i}^{*}\left(a, \theta_{f} a+\epsilon\right) .\right. \\
\left.-N_{i}^{*}\left(a, \theta_{f} a-\epsilon\right)\right]>0\end{array}$ & $\begin{array}{c}\text { pos. if } q>0 \\
\text { no change if } q=0\end{array}$ \\
\hline$N_{f}^{*}(a, \bar{w})$ & $>0$ & $<0$ & $\begin{array}{r}\lim _{\epsilon \rightarrow 0}\left[N_{f}^{*}\left(a, \theta_{f} a+\epsilon\right)\right. \\
\left.-N_{f}^{*}\left(a, \theta_{f} a-\epsilon\right)\right]<0\end{array}$ & $\begin{array}{c}- \\
\lim _{\epsilon \rightarrow 0}\left[\bar{N}_{f}^{*}\left(a, \theta_{f} a+\epsilon\right)\right. \\
\left.-\bar{N}_{f}^{*}\left(a, \theta_{f} a-\epsilon\right)\right]<0\end{array}$ \\
\hline $\bar{N}_{f}^{*}(a, \bar{w})$ & $>0 *$ & $>0$ &
\end{tabular}

*If $\bar{w}>b_{E} a /\left(1-\left(1-b_{E}\right) q\right)$.

\section{Appendix A}

We demonstrate here that in the absence of a minimum wage legislation, heightened employer market power in the presence of a binding NRC decreases the reservation wage as defined in (7). To this end, suppose to begin with that employers are able to commit ex ante to refrain from reneging on an agreed upon wage contract. The NRC is no longer warranted, and employer profits are driven to zero from the FEC. It follows therefore from (21) that

$$
H^{*}\left(w^{e} ; a, 0\right)=\frac{\left(1-b_{E}\right) \rho_{i} a}{a-w^{e}} .
$$

Furthermore, in the absence of an NRC,

$$
w_{i}^{+}(a, 0)=w_{i}^{F E}(a)=b_{E} a+\left(1-b_{E}\right)\left(1-\rho_{i}\right) a .
$$

Let the corresponding reservation wage be $\hat{w}_{r}^{e}(a, \bar{w})$, where from (7), upon integrating by parts:

$$
\hat{w}_{r}^{e}(a, \bar{w})=\frac{\beta_{N}}{1-b_{N}}\left[\left(w_{i}^{F E}(a)-\hat{w}_{r}^{e}(a, \bar{w})\right)-\int_{\hat{w}_{r}^{e}(a, \bar{w})}^{w_{i}^{F E}} \frac{\left(1-b_{E}\right) \rho_{i} a}{a-w^{e}} d w^{e}\right] .
$$

\footnotetext{
${ }^{29}$ The equilibrium employer profits $\bar{V}(a, \bar{w})$ has been demonstrated in Proposition 5 . From Section 4.3, equilibrium labor allocations are given by: $U^{*}(a, \bar{w})=\delta / \Delta, N_{i}^{*}(a, \bar{w})=\left(H_{i}^{*}\left(w_{i}^{N R}(a, \bar{w}) ; a, \bar{w}\right)-H_{i}^{*}\left(w_{i}^{-}(a, \bar{w}) ; a, \bar{w}\right)\right) / \Delta$, $N_{f}^{*}(a, \bar{w})=\left(1-H_{i}^{*}\left(w_{i}^{N R}(a, \bar{w}) ; a, \bar{w}\right)\right) / \Delta$, and $\bar{N}_{f}^{*}(a, \bar{w})=\left(H_{f}^{*}(\bar{w} ; a, \bar{w})-H_{i}^{*}\left(w_{i}^{N R}(a, \bar{w}) ; a, \bar{w}\right) / \Delta\right.$ where $\Delta=\left[1+\delta-H^{*}\left(w_{i}^{-}(a, \bar{w}) ; a, \bar{w}\right)\right] / \bar{N}(a)$.
} 
Suppose instead that employers are unable to commit, and the NRC is binding. It follows that

$$
w_{i}^{+}(a, 0)=w_{i}^{N R}(a, 0)=b_{E} a .
$$

Employer profits are now strictly positive, and

$$
H^{*}\left(w^{e} ; a, 0\right)=\frac{\left(1-b_{E}\right) a}{a-w^{e}} .
$$

Let the corresponding reservation wage be $\tilde{w}_{r}^{e}(a)$, where:

$$
\tilde{w}_{r}^{e}(a, \bar{w})=\frac{\beta_{N}}{1-b_{N}}\left[\left(w_{i}^{F E}(a)-\Delta-\hat{w}_{r}^{e}(a, \bar{w})\right)-\int_{\hat{w}_{r}^{e}(a, \bar{w})}^{w_{i}^{F E}-\Delta} \frac{\left(1-b_{E}\right) \rho_{i} a+\Delta}{a-w^{e}} d w^{e}\right]
$$

where $\Delta \equiv\left(1-b_{E}\right)\left(1-\rho_{i}\right) a>0$. It follows immediately upon routine differentiation that $\tilde{w}_{r}^{e}(a, \bar{w})$ is strictly decreasing in $\Delta$, or equivalently, a binding $\mathrm{NRC}$, and the corresponding employer market power implies a strict reduction in the reservation wage. Indeed,

$$
\frac{\partial \tilde{w}_{r}^{e}(a, \bar{w})}{\partial \Delta}=-\frac{\beta_{N}}{1-b_{N}}\left[\int_{\hat{w}_{r}^{e}(a, \bar{w})}^{w_{i}^{F E}-\Delta} \frac{1}{a-w^{e}} d w^{e}\right]
$$

is proportional to $\beta_{N}$, all else equal. Thus, the higher the discount factor $\beta_{N}$, the larger will be the reduction in the reservation offer in the presence of employer market power.

\section{Appendix B}

Proof of Proposition 8: We begin with the following result:

Lemma 1 1. There exists a $\hat{\beta}_{N} \in[0,1]$ such that for all $\beta_{N}<\hat{\beta}_{N}, \Omega_{i}^{e}(a, \bar{w})$ is nonempty and $w_{i}^{-}(a, \bar{w})=\max \left\{q \bar{w}, w_{r}^{e}(a, \bar{w})\right\}<w_{i}^{N R}(a, \bar{w})$. 2. The reservation offer $w_{r}^{e}(a, \bar{w})$ is always monotonically increasing in $\bar{w}$ for $(a, \bar{w}) \in A_{f}^{N R}, A_{i}^{N R}$, and monotonically increasing in $\bar{w}$ for $(a, \bar{w}) \in A_{f}^{F E}$ if $q$ is sufficiently small. 3. For any $(a, \bar{w})$ pair, $\partial w_{r}^{e}(a, \bar{w}) / \partial \bar{w} \rightarrow 0$ as $\beta_{N} \rightarrow 0$.

\section{Proof:}

1. Denote the right hand side of $(7)$ as $\Phi\left(w_{r}^{e}\right)$ :

$$
\Phi\left(w_{r}^{e}\right) \equiv \frac{\beta_{N}}{1-b_{N}} \int_{w_{r}^{e}}^{w^{+}(a, \bar{w})}\left(x-w_{r}^{e}\right) d H(x ; a, \bar{w}) .
$$

Three observations follow: (i) $\Phi\left(w_{r}^{e}\right)$ is monotonically decreasing in $w_{r}^{e}$ and $\beta_{N}$ respectively, (ii) $\Phi\left(w^{+}(a, \bar{w})\right)=0$, and (iii) $\Phi(0)>0$. Thus,

$$
w^{+}(a, \bar{w})-\Phi\left(w^{+}(a, \bar{w})\right)>0, \text { and } 0-\Phi(0)<0 .
$$

It follows that the implicit solution to $(7), w_{r}^{e}(a, \bar{w})$, is unique, and lies in the interval $\left[0, w^{+}(a, \bar{w})\right]$. Furthermore, routine differentiation shows that $w_{r}^{e}(a, \bar{w})$ is monotonically increasing in $\beta_{N}$, with $w_{r}^{e}(a, \bar{w}) \rightarrow 0$ as $\beta_{N} \rightarrow 0$. Define

$$
\hat{\beta}_{N}=\max \left\{\beta_{N} \in[0,1] \mid w_{r}^{e}(a, \bar{w}) \leq w_{i}^{N R}(a, \bar{w})\right\} .
$$

By monotonicity of $w_{r}^{e}(a, \bar{w})$ with respect to $\beta_{N}, \hat{\beta}_{N}$ is uniquely defined. Furthermore, for any $\beta<\hat{\beta}_{N}, w_{r}^{e}(a, \bar{w})<w_{i}^{N R}(a, \bar{w})$, and $\Omega_{i}^{e}(a)=\left[\max \left\{q \bar{w}, w_{r}^{e}(a, \bar{w})\right\}, w_{i}^{N R}(a, \bar{w})\right]$ is thus non-empty. 
2. Assuming first that $\beta_{N}<\hat{\beta}_{N}$ so that informal and formal employment co-exist from Lemma 1.1, it follows from (7) upon integrating by parts that for $(a, \bar{w}) \in A_{f}^{N R}(\bar{w})$,

$$
\operatorname{sgn}\left\{\frac{\partial w_{r}^{e}(a, \bar{w})}{\partial \bar{w}}\right\}=\operatorname{sgn}\left\{\beta_{N} \int_{w_{r}^{e}}^{w_{i}^{N R}} \frac{1}{a-w^{e}} d w^{e}+\beta_{N} \int_{w_{i}^{N R}}^{w^{+}} \frac{1}{a-w^{e}} d w^{e}\right\} \geq 0
$$

if and only if $\beta_{N} \geq 0$. The cases of $(a, \bar{w}) \in A_{i}^{N R}(\bar{w}), A_{i}^{F E}(\bar{w})$ and $A_{i}^{N R}(a)$ can be analogously obtained by routine differentiation, upon integration (7) by parts.

3. This follows directly from (24) above, where by inspection $\partial w_{r}^{e}(\cdot) / \partial \bar{w} \rightarrow 0$ if $\beta_{N} \rightarrow 0$.

Henceforth, we consider $\beta_{N}$ sufficiently small, and in particular $\beta_{N}<\hat{\beta}_{N}$, such that $\Omega_{i}^{e}(a, \bar{w})$ is nonempty and $w_{i}^{-}(a, \bar{w})=\max \left\{q \bar{w}, w_{r}^{e}(a, \bar{w})\right\}<w_{i}^{N R}(a, \bar{w})$. Furthermore, recall that $w_{i}^{+}(a, \bar{w})=$ $w_{i}^{N R}(a, \bar{w})$. Thus,

$$
\begin{aligned}
& p_{i}(a, \bar{w})=\int_{w^{e} \in \Omega_{i}^{e}(a, \bar{w})} d H^{*}\left(w^{e} ; a, \bar{w}\right)=H_{i}^{*}\left(w_{i}^{N R}(a, \bar{w}) ; a, \bar{w}\right)-H_{i}^{*}\left(w_{i}^{-}(a, \bar{w}) ; a, \bar{w}\right), \\
& p_{f}(a, \bar{w})=\int_{w^{e} \in \Omega_{f}^{e}(a, \bar{w})} d H^{*}\left(w^{e} ; a, \bar{w}\right)=1-H_{i}^{*}\left(w_{i}^{N R}(a, \bar{w}) ; a, \bar{w}\right) .
\end{aligned}
$$

From (19),

$$
\begin{aligned}
U^{*}(a, \bar{w})=\frac{\delta}{\Delta}, \quad N_{i}^{*}(a, \bar{w}) & =\frac{H_{i}^{*}\left(w_{i}^{N R}(a, \bar{w}) ; a, \bar{w}\right)-H_{i}^{*}\left(w_{i}^{-}(a, \bar{w}) ; a, \bar{w}\right)}{\Delta}, \\
N_{f}^{*}(a, \bar{w}) & =\frac{1-H_{i}^{*}\left(w_{i}^{N R}(a, \bar{w}) ; a, \bar{w}\right)}{\Delta},
\end{aligned}
$$

where $\Delta=\left[1+\delta-H^{*}\left(w_{i}^{-}(a, \bar{w}) ; a, \bar{w}\right)\right] / \bar{N}(a)$. In addition, the number of workers paid exactly the minimum wage is given by

$$
\bar{N}_{f}^{*}(a, \bar{w})=\frac{H_{f}^{*}(\bar{w} ; a, \bar{w})-H_{i}^{*}\left(w_{i}^{N R}(a, \bar{w}) ; a, \bar{w}\right)}{\Delta}
$$

when formal and informal employment co-exist, and when $\bar{w}>b_{E} a /\left(1-\left(1-b_{E}\right) q\right)$ as noted in Section 5 and Figure 3.

Our objective is to demonstrate Proposition 8 by confirming, entry-by-entry, the comparative statics responses displayed in Table 2. The expected employer profits response to a minimum wage has already been shown in Proposition 5. What remain to be demonstrated are the responses of unemployment $U^{*}(a, \bar{w})$, informal employment $N_{i}^{*}(a, \bar{w})$, formal employment $N_{f}^{*}(a, \bar{w})$, and the equilibrium size of the spike at the minimum wage $\bar{N}_{f}^{*}(a, \bar{w})$ subsequent to a minimum wage hike.

In what follows, we demonstrate the comparative statics responses displayed in the second and fourth column of Table 2. These are respectively the case of coexisting formal and informal employment, $A_{f}^{N R}$, and the transition from coexistence to informal employment only. The comparative statics responses displayed in the third and fifth column can be shown in analogous fashion, and are available upon request.

Coexistence of Formal and Informal Employment $\left(A_{f}^{N R}\right)$

To begin with, consider minimum wages that are sufficiently small, so that $(a, \bar{w}) \in A_{f}^{N R}$, or $\bar{w}<$ $a\left(1-\rho_{f}\right)$. From Table 1, we have

$$
H^{*}\left(w^{e} ; a, \bar{w}\right)= \begin{cases}H_{i}^{*}\left(w^{e} ; a, \bar{w}\right)=\left(1-b_{E}\right)\left(a-\bar{w}-\left(\rho_{f}-\rho_{i}\right) a\right) /\left(a-w^{e}\right), & w^{e} \leq w_{i}^{N R} \\ H_{f}^{*}\left(w^{e} ; a, \bar{w}\right)=\left(1-b_{E}\right)(a-\bar{w}) /\left(a-w^{e}\right), & w^{e} \in\left(w_{i}^{N R}, w_{f}^{N R}\right] .\end{cases}
$$


Unemployed Workers. For $\beta_{N}$ sufficiently small, $w_{i}^{-}(a, \bar{w})=\max \left\{q \bar{w}, w_{r}^{e}(a, \bar{w})\right\}$. Suppose therefore that $w_{i}^{-}(a, \bar{w})=q \bar{w}$. Thus

$$
H_{i}^{*}\left(w_{i}^{-}(a, \bar{w}) ; a, \bar{w}\right)=\frac{\left(1-b_{E}\right)\left(a-\bar{w}-\left(\rho_{f}-\rho_{i}\right) a\right.}{a-q \bar{w}}
$$

From $(28), H^{*}\left(w_{i}^{-}(a, \bar{w}) ; a, \bar{w}\right)$ is strictly decreasing in the minimum wage $\bar{w}$. From (25), it follows that $U^{*}(a, \bar{w})$ is likewise strictly decreasing in $\bar{w}$.

Suppose instead that $w_{i}^{-}(a, \bar{w})=w_{r}^{e}(a, \bar{w})$. Now,

$$
H_{i}^{*}\left(w_{i}^{-}(a, \bar{w}) ; a, \bar{w}\right)=\frac{\left(1-b_{E}\right)\left(a-\bar{w}-\left(\rho_{f}-\rho_{i}\right) a\right)}{a-w_{r}^{e}(a, \bar{w})} .
$$

Now from (29) and Lemma $1.3, H^{*}\left(w_{i}^{-}(a, \bar{w}) ; a, \bar{w}\right)$ is strictly decreasing in the minimum wage $\bar{w}$ if $\beta_{N}$ is sufficiently small. From $(25)$, it follows that $U^{*}(a, \bar{w})$ is likewise strictly decreasing in $\bar{w}$.

Taken together, equilibrium unemployment is always strictly decreasing with respect to $\bar{w}$ for all $(a, \bar{w}) \in A_{f}^{N R}$ so long as $\beta_{N}$ is sufficiently small.

Informal Workers. From Lemma 1,

$$
\begin{aligned}
p_{i}(a, \bar{w}) & =H_{i}^{*}\left(w_{i}^{N R}(a, \bar{w}) ; a, \bar{w}\right)-H_{i}^{*}\left(w_{i}^{-}(a, \bar{w}) ; a, \bar{w}\right) \\
& =\frac{\left(1-b_{E}\right)\left(a-\bar{w}-\left(\rho_{f}-\rho_{i}\right) a\right)}{a-w_{i}^{N R}(a, \bar{w})}-\frac{\left(1-b_{E}\right)\left(a-\bar{w}-\left(\rho_{f}-\rho_{i}\right) a\right)}{a-w_{i}^{-}(a, \bar{w})} .
\end{aligned}
$$

From $(30), p_{i}(a, \bar{w})$ is strictly decreasing with respect to $\bar{w}$ if $w_{i}^{-}(a, \bar{w})=q \bar{w}$. If instead $w_{i}^{-}(a, \bar{w})=$ $w_{r}^{e}\left(a, \bar{w}\right.$, it follows from Lemma 1.2 and 1.3 that $p_{i}(a, \bar{w})$ continues to be strictly decreasing with respect to $\bar{w}$ if $\beta_{N}$ is sufficiently small.

From (30) as well as (28) and (29) above, it can be readily verified that $N_{i}^{*}(a, \bar{w})$ is strictly decreasing with respect to $\bar{w}$ for all $(a, \bar{w}) \in A_{f}^{N R}$ so long as $\beta_{N}$ is sufficiently small.

Formal Employment. From (29) and (30) above, since equilibrium unemployment and informal employment are both decreasing with respect to $\bar{w}$, formal employment must rise with the minimum wage.

Minimum Wage Workers. As shown in Section 5 and Figure 3, a spike at the minimum wage occurs whenever $\bar{w}>b_{E} a /\left(1-\left(1-b_{E}\right) q\right)$. From (26), the number of workers earning higher than the minimum wage is

$$
N_{f}^{*}(a, \bar{w})-\bar{N}_{f}^{*}(a, \bar{w})=\frac{1-H_{f}^{*}(\bar{w} ; a, \bar{w})}{\Delta}=\frac{b_{E}}{\Delta}
$$

From (31) above, it follows straightforwardly that the number of workers earning higher than the minimum wage $N_{f}^{*}(a, \bar{w})-\bar{N}_{f}^{*}(a, \bar{w})$ is strictly decreasing in $\bar{w}$. Since $N_{f}^{*}(a, \bar{w})$ rises with the minimum wage as shown above, it must be the case that the number of workers earning exactly the minimum wage rises with the minimum wage.

\section{Transition}

As the minimum wage rises beyond the critical threshold $a \theta_{f}$, there is full informalization as shown in Proposition 5. To determine the direction of the discrete change in equilibrium labor allocation, use Table 1 to ascertain the following difference:

$$
\begin{aligned}
& \lim _{\epsilon \rightarrow 0} H_{i}^{*}\left(w^{-}\left(a, a \theta_{f}+\epsilon\right) ; a, a \theta_{f}+\epsilon\right)-H_{i}^{*}\left(w^{-}\left(a, a \theta_{f}-\epsilon\right) ; a, a \theta_{f}-\epsilon\right) \\
= & \left(1-b_{E}\right)\left(a-a \theta_{f} q\right) /\left(a-w^{-}\left(a, a \theta_{f}\right)\right)-\left(1-b_{E}\right) \rho_{i} a /\left(a-w^{-}\left(a, a \theta_{f}\right)\right)
\end{aligned}
$$


Suppose that $\beta_{N}$ is sufficiently small, so that $w_{r}^{e}(a, \bar{w}) \leq q \bar{w}$. It follows that $w^{-}\left(a, a \theta_{f}\right)=q \bar{w}$, and:

$$
\begin{aligned}
& \lim _{\epsilon \rightarrow 0} H_{i}^{*}\left(w^{-}\left(a, a \theta_{f}+\epsilon\right) ; a, a \theta_{f}+\epsilon\right)-H_{i}^{*}\left(w^{-}\left(a, a \theta_{f}-\epsilon\right) ; a, a \theta_{f}-\epsilon\right) \\
= & \left.\left(1-b_{E}\right)\left(a-q \theta_{f} a\right) /\left(a-q \theta_{f} a\right)-\left(1-b_{E}\right) \rho_{i} a /\left(a-q \theta_{f} a\right)\right) \\
= & \left(1-b_{E}\right) a\left(1-\rho_{i}-q \theta_{f}\right) /\left(a-q \theta_{f} a\right)>0 .
\end{aligned}
$$

under the assumption of contractual dualism, or, $q<1-\rho_{i}$. From (32), it follows that there is a discrete increase in equilibrium unemployment as the minimum wage rises beyond $a \theta_{f}$, with $\lim _{\epsilon \rightarrow 0} U^{*}\left(a \theta_{f}+\right.$ $\epsilon)-U^{*}\left(a, a \theta_{f}-\epsilon\right)>0$.

Now turning to informal employment, consider now the following difference, supposing once again that $\beta_{N}$ is sufficiently small, so that $w_{r}^{e}(a, \bar{w}) \leq q \bar{w}$ :

$$
\begin{aligned}
& \lim _{\epsilon \rightarrow 0}\left[H_{i}^{*}\left(w_{i}^{N R}\left(a, a \theta_{f}+\epsilon\right)-H_{i}^{*}\left(w^{-}\left(a, a \theta_{f}+\epsilon\right) ; a, a \theta_{f}+\epsilon\right)\right]\right. \\
& -\lim _{\epsilon \rightarrow 0}\left[H_{i}^{*}\left(w_{i}^{N R}\left(a, a \theta_{f}-\epsilon\right)-H_{i}^{*}\left(w^{-}\left(a, a \theta_{f}-\epsilon\right) ; a, a \theta_{f}-\epsilon\right)\right]\right. \\
= & 1-\frac{\left(1-b_{E}\right)\left(a-a \theta_{f} q\right)}{a-a \theta_{f} q}-\frac{\left(1-b_{E}\right) \rho_{i} a}{\left(1-b_{E}\right)\left(a-a \theta_{f} q\right)}+\frac{\left(1-b_{E}\right) \rho_{i} a}{a-a \theta_{f} q} \\
= & \frac{b_{E} a\left(1-\rho_{i}-q \theta_{f}\right)}{a-a \theta_{f} q}>0
\end{aligned}
$$

under the assumption of contractual dualism, $q<1-\rho_{i}$. From (33), as well as (32) above, it follows that there is a discrete increase in equilibrium informal employment as the minimum wage rises beyond $a \theta_{f}$, with $\lim _{\epsilon \rightarrow 0} N_{i}^{*}\left(a \theta_{f}+\epsilon\right)-N_{i}^{*}\left(a, a \theta_{f}-\epsilon\right)>0$.

\section{References}

Albrecht, James, Lucas Navarro and Susan Vroman. 2009. "The Effects of Labor Market Policies in an Economy with an Informal Sector," Economic Journal 119: 1105 - 1129.

Baanante, Miguel J. (2005). "Minimum Wage Effects under Endogenous Compliance. evidence from Peru', available at http://www.grade.org.pe/download/docs/Minimum\%20wag es\%20in\%20Peru\%20M. \%20Jaramillo.pdf.

Bell, Linda. 1997. "The Impact of Minimum Wages in Mexico and Columbia," Journal of Labor Economics 15 (3): S102-S135.

Boeri, Tito and Pietro Garibaldi. 2007. "Shadow Sorting," in Jeffrey Frankel and Christopher Pissarides (eds.) NBER International Seminar on Macroeconomics 2005. MIT Press. pp. $125-163$.

Card, David and Krueger, Alan B. (1995). Myth and Measurement: The New Economics of the Minimum Wage, Princeton: Princeton University Press. 
Carneiro, Francisco Gairoa and Carlos Enrique Leite Corseuil. 2001. "Minimum Wage Effects on Wages and Employment: Evidence from Time Series and Longitudinal Data," IPEA Working Paper No. 849, December.

Chari, V. V., Diego Restuccia, and Carlos Urrutia. 2005. "On-The-Job Training, Limited Commitment and Firing Costs," Working Paper, Federal Reserve Bank of Minneapolis. Charlot, Olivier, Franck Malherbet and Cristina Terra. 2011. "Product Market Regulation, Firm Size, Unemployment and Informality in Developing Economies," IZA Discussion Papers 5519 .

de Soto, Hernando. 2003. The Mystery of Capital: Why Capitalism Triumps in the West and Fails Everywhere Else. New York: Basic Books.

Fajnzylber, Pablo. 2001. "Minimum Wage Effects Throughout the Wage Distribution: Evidence from Brazil's Formal and Informal Sectors," Department of Economics, Universidade Federal de Minas Gerais, unpublished.

Fields, Gary. 2004. "A Guide to Multisector Labor Market Models," Cornell University School of Industrial and Labor Relations Working Papers 11-1-2004.

Gindling, Tim H. and Katherine Terrell. 2009. "Minimum Wages and Employment in Various Sectors in Honduras," Labour Economics 16 (3): 291-303.

Gindling, Tim H. and Katherine Terrell. 2007. "The Effects of Multiple Minimum Wages throughout the Labor Market: The Case of Costa Rica," Labour Economics 14: 485511.

Gindling, Tim H. and Katherine Terrell. 2006. "Minimum Wages, Globalization and Poverty in Honduras," IZA Discussion Paper: 2497.

Gong, Xiaodong, and Arthur Van Soest. 2002. "Wage Differentials and Mobility in the Urban Labour Market: A Panel Data Analysis for Mexico," Labour Economics 9(4): 513 - 259. Gong, Xiaodong, Arthur Van Soest, and Elizabeth Villagomez. 2004. "Mobility in the Urban Labor Market: A Panel Data ANalysis for Mexico," Economic Development and Cultural Change 53(1): 1 - 36 .

Guha-Khasnobis, Basudeb, Ravi Kanbur and Elinor Ostrom. 2006. Linking the Formal and Informal Economy Concepts and Policies. Oxford University Press. Oxford, U. K.

Harris, John R. and Michael P. Todaro. 1070. "Migration, Unemployment and Development: A Two-Sector Analysis," American Economic Review 60 (1): 126142. 
Kanbur, Ravi. 2009. "Conceptualising Informality: Regulation and Enforcement." Indian Journal of Labour Economics 52 (1): 33-42.

Lemos, Sara. 2009. "Minimum Wage Effects in a Developing Country," Labour Economics 16: 224-237.

Lemos, Sara. 2004. "The Effects of the Minimum Wage in the Formal and Informal Sectors in Brazil," IZA Discussion Paper no. 1089.

Levy, Santiago. 2007. Good Intentions, Bad Outcomes: Social Policy, Informality, and Economic Growth in Mexico. Washington D.C.: Brookings Institution Press.

Maloney, William and Jairo Nunez. 2004. "Measuring the Impact of Minimum Wages: Evidence from Latin America". In J. Heckman and C. Pagès (eds.) Law and Employment. Lessons from Latin America and the Caribbean. Cambridge, MA: NBER.

Maloney, William F. 1999. "Does Informality Imply Segmentation in Urban Labor Markets? Evidence from Sectoral Transitions in Mexico". The World Bank Economic Review 13: 275-302.

Ramey, Gary, and Joel Watson. 1997. "Contractual Fragility, Job Destruction, and Business Cycles," Quarterly Journal of Economics 112 (3): 873 - 911.

Rauch, James E. 1991. "Modelling the Informal Sector Formally," Jounal of Development Economics 35: 3347 .

Portugal, Pedro and Ana Rute Cardoso. 2002. "Disentangling the Minimum Wage Puzzle: An Analysis of Worker Accessions and Separations," IZA Discussion Paper 544.

Schneider, Friedrich, and Dominik H. Enste. 2000. "Shadow Economies: Size, Causes, and Consequences," Journal of Economic Literature 38 (1): 77 - 114.

Stigler, George J. 1946. 'The Economics of Minimum Wage Legislation', American Economic Review 36 (3): 358-65.

Strobl, Eric and Frank Walsh. 2001. "Minimum Wage and Compliance: The Case of Trinidad and Tobago," Economic Development and Cultural Change 51 (2): 427-450.

Thomas, Jim J. 1992. Informal Economic Activity. (LSE Handbooks in Economics). The University of Michigan Press. 


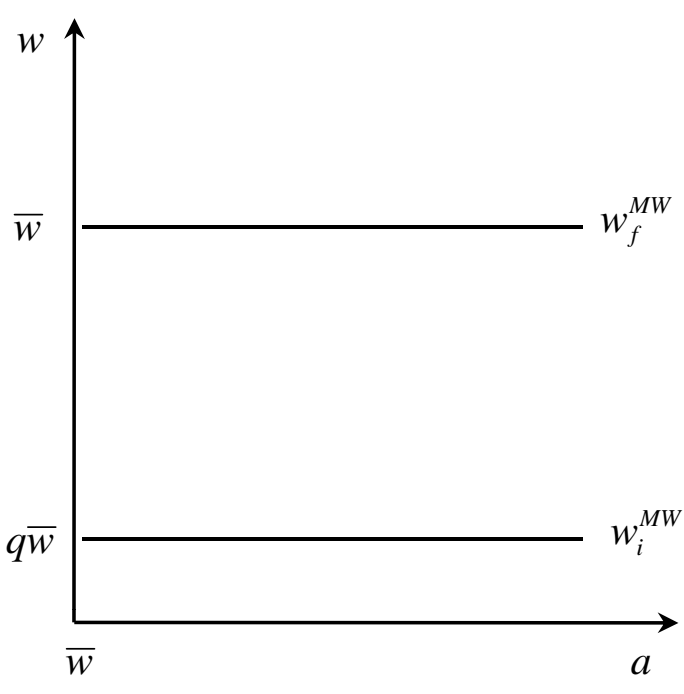

Figure $1 a$

Minimum Wage Constraint MWC

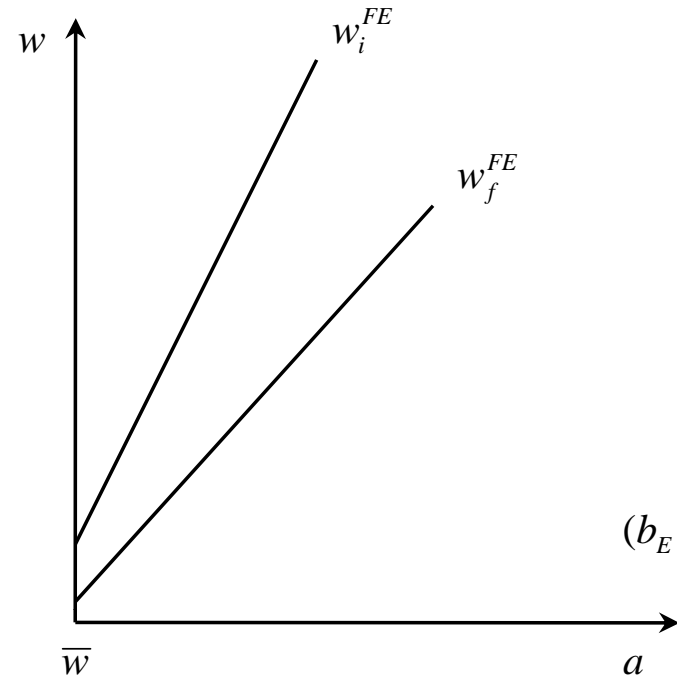

Figure $1 b$

Free Entry Constraint FEC

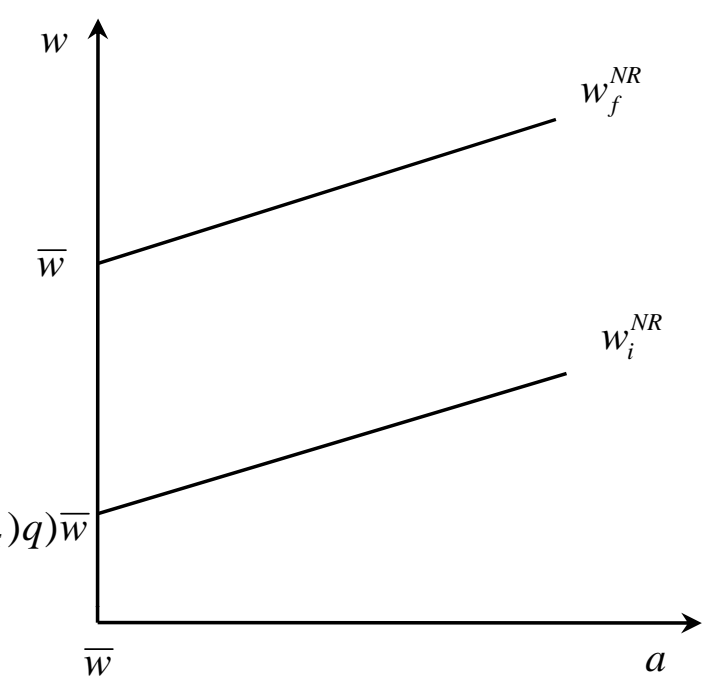

Figure 1c

No Reneging Constraint NRC 


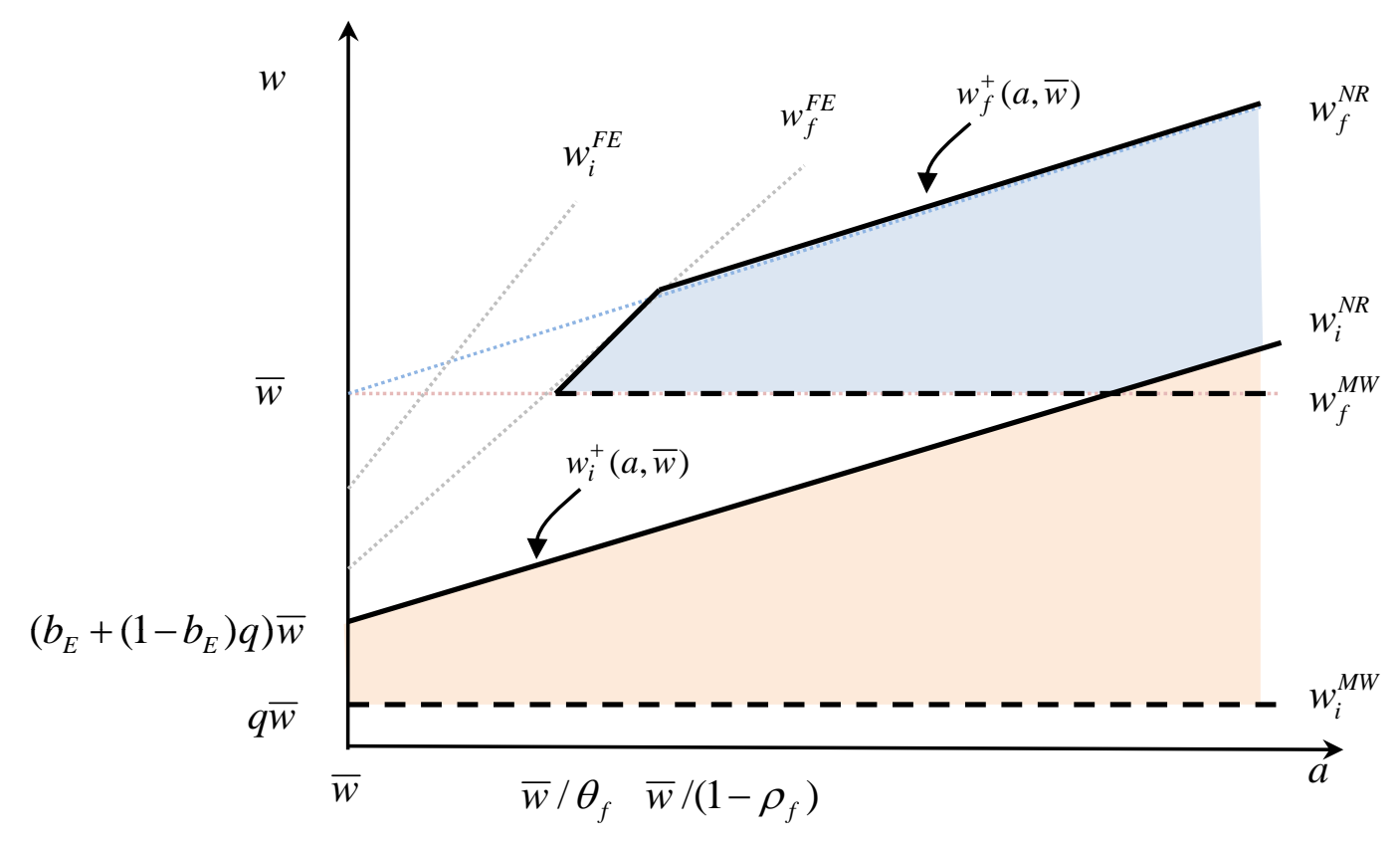

Figure 2

Wage Dualism

\begin{tabular}{|ll}
\hline$w_{i}^{M W}=q \bar{w}$ & $w_{f}^{M W}=\bar{w}$ \\
$w_{i}^{F E}=b_{E} a+\left(1-b_{E}\right)\left(1-\rho_{i}\right) a=\theta_{i} a$ & $w_{f}^{F E}=b_{E} a+\left(1-b_{E}\right)\left(1-\rho_{f}\right) a=\theta_{f} a$ \\
$w_{i}^{N R}=b_{E} a+\left(1-b_{E}\right) q \bar{w}$ & $w_{f}^{N R}=b_{E} a+\left(1-b_{E}\right) \bar{w}$ \\
\hline
\end{tabular}




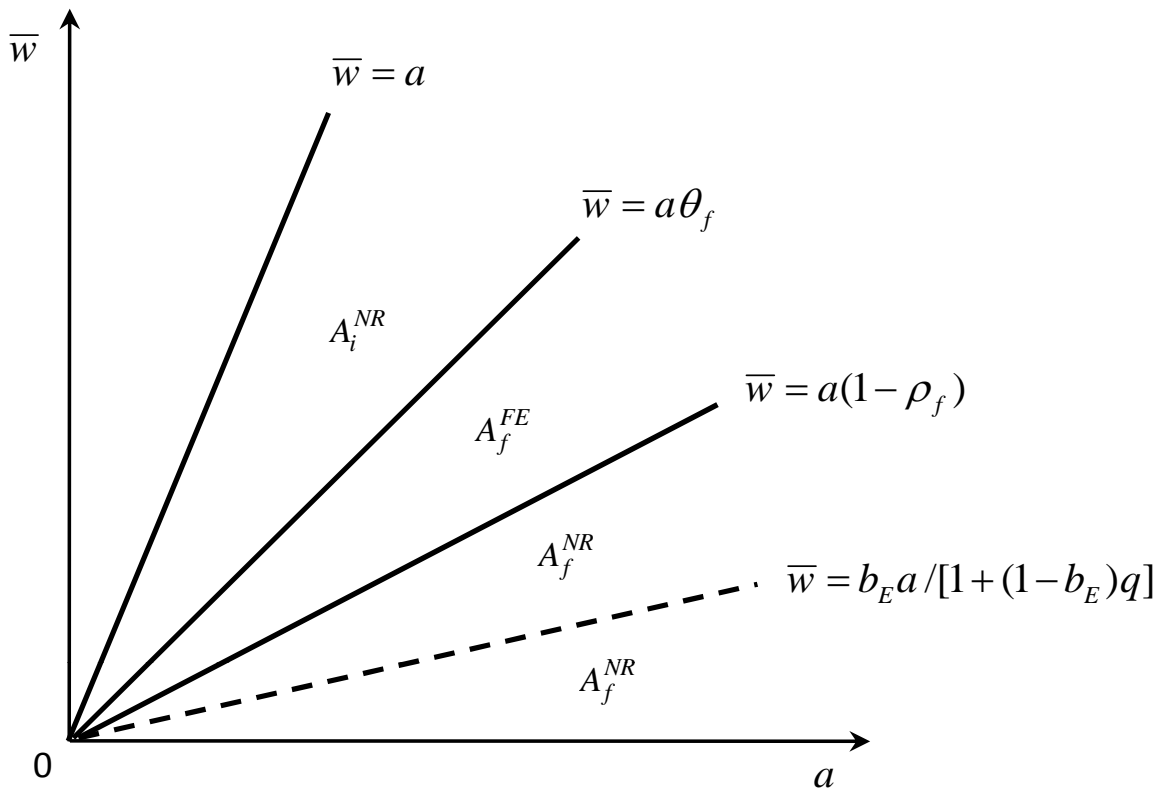

Figure 3

Minimum wage, the FEC and the NRC 


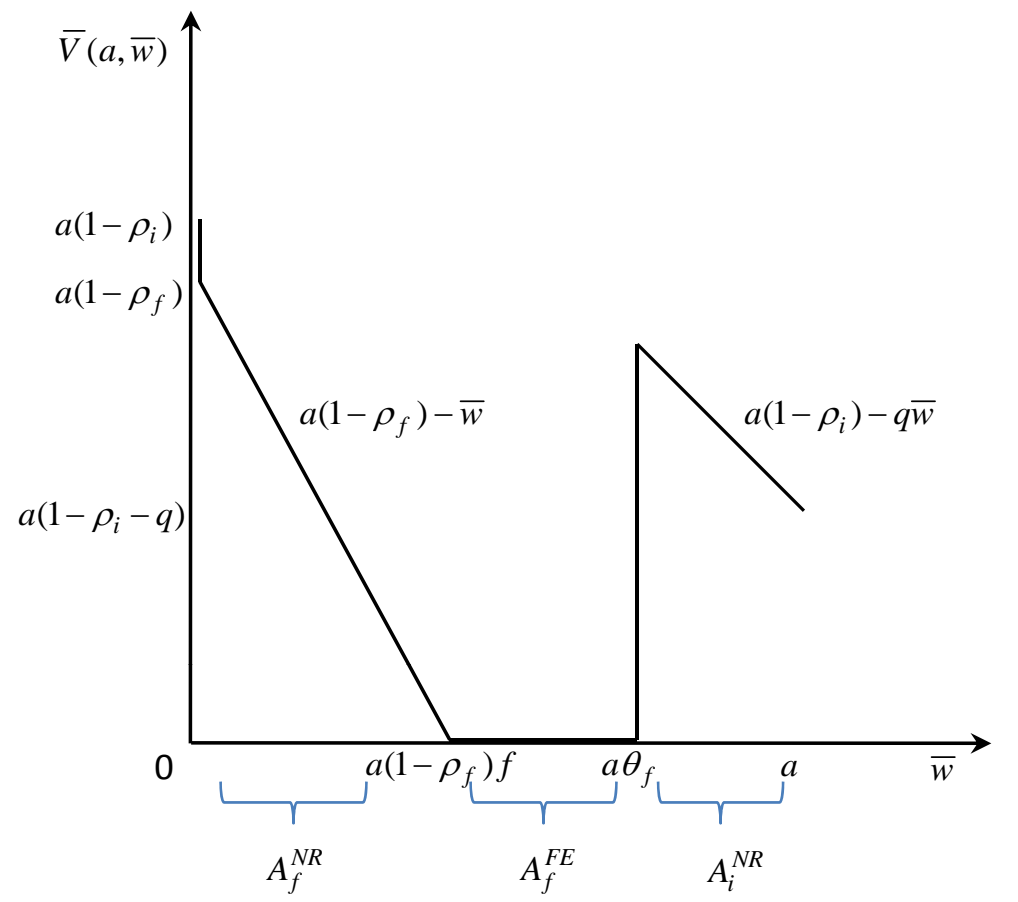

Figure 4a

Expected Profits and the Minimum Wage $(q>0)$

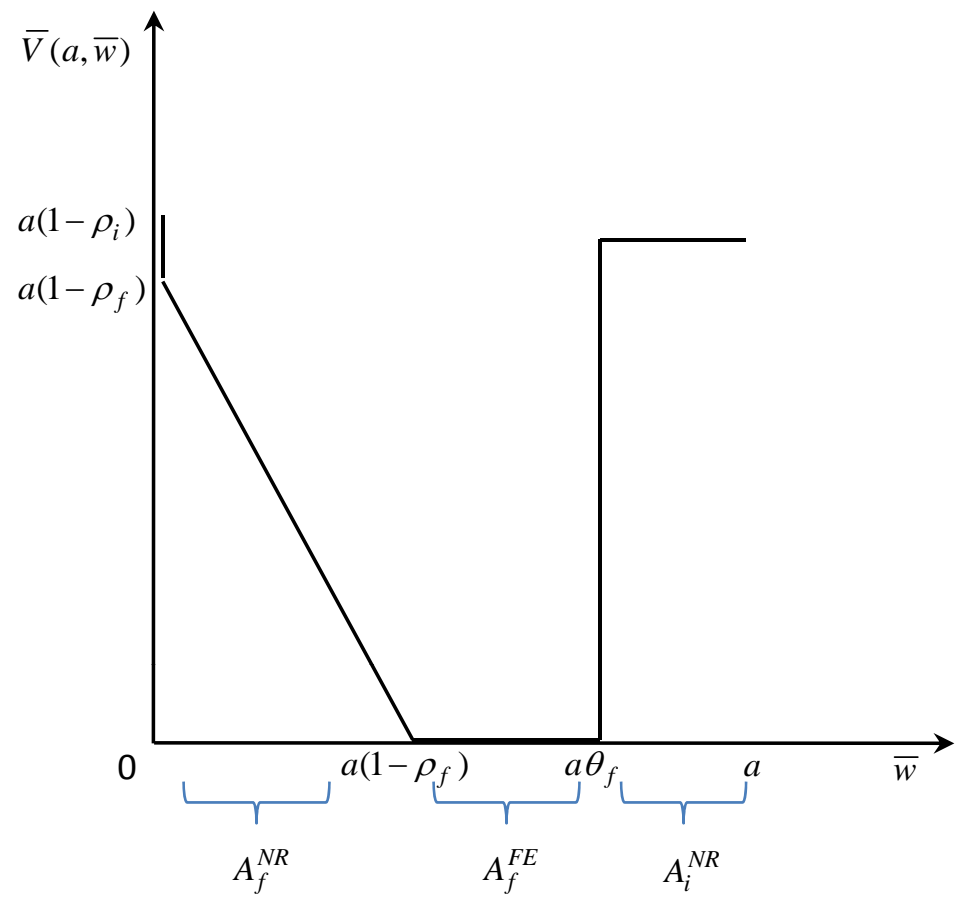

Figure $4 b$

Expected Profits and the Minimum Wage $(q=0)$ 


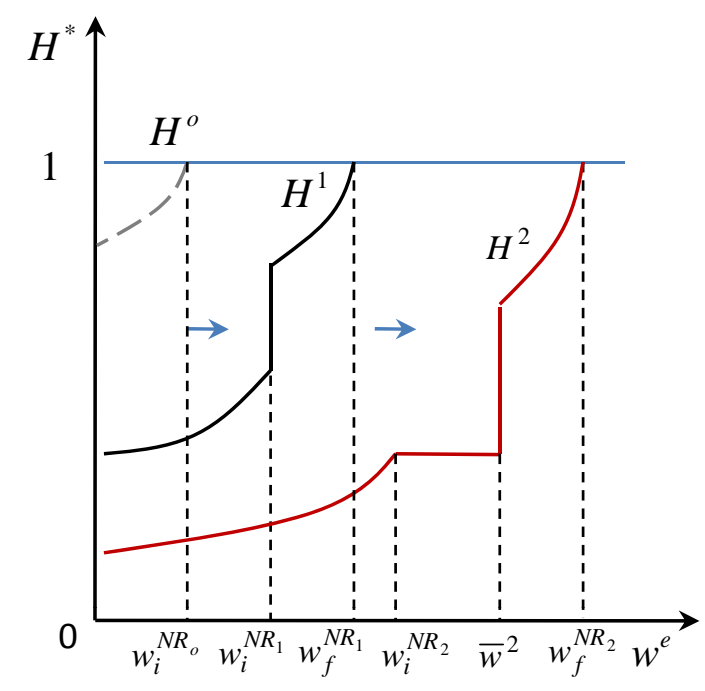

Figure $5 a$

Minimum Wage with a

Binding Formal NRC, and Binding Informal NRC

$(q>0)$

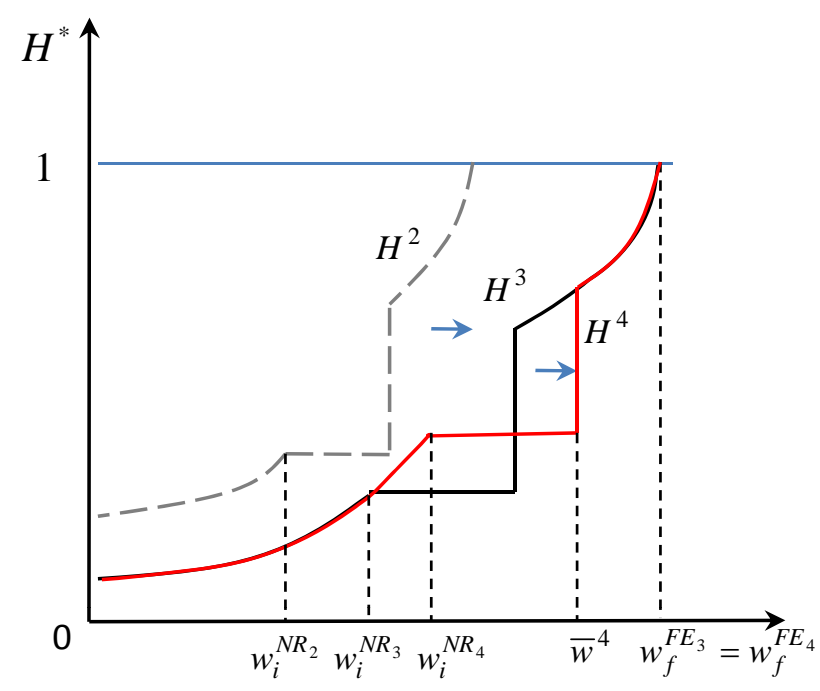

Figure $5 b$

Minimum Wage with a

Binding Formal FEC, and

Binding Informal NRC

$$
(q>0)
$$

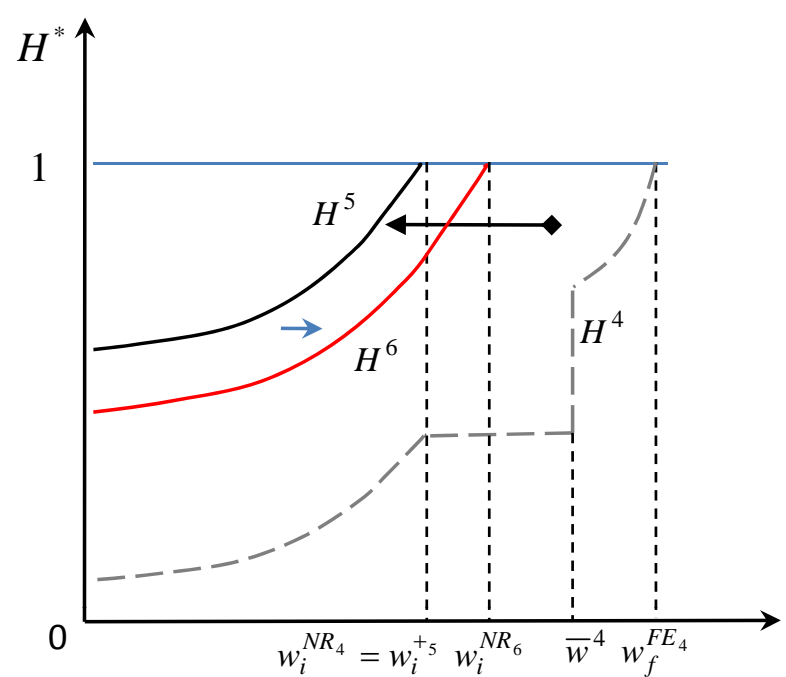

Figure 5c

Minimum Wage with a Binding Informal NRC

$(q>0)$ 


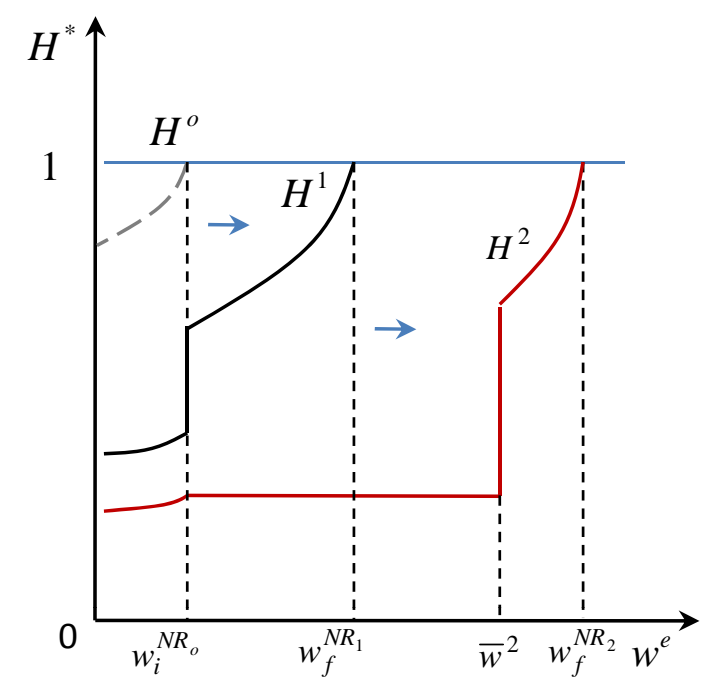

Figure 6a

Minimum Wage with a

Binding Formal NRC, and Binding Informal NRC

$(q=0)$

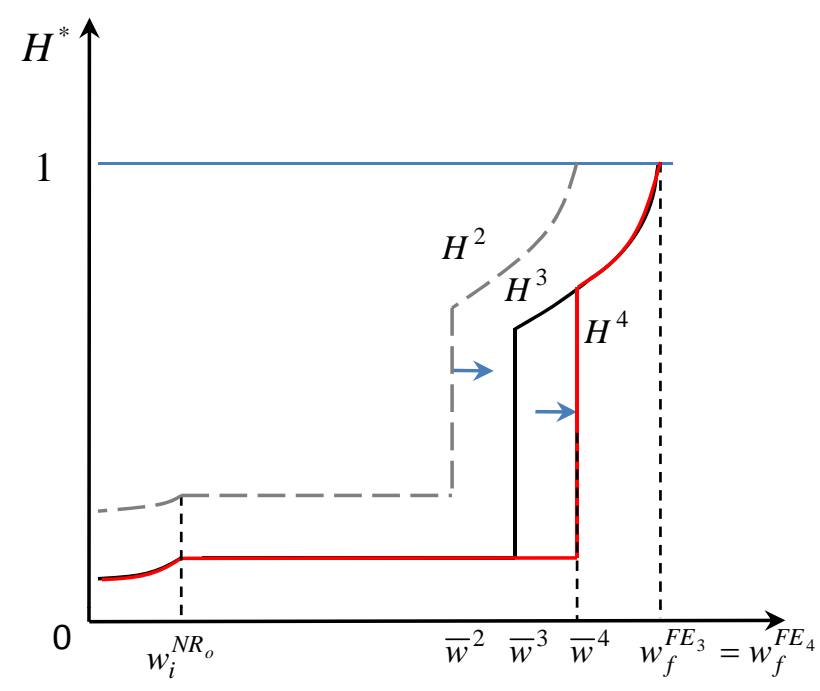

Figure 6b

Minimum Wage with a

Binding Formal FEC, and

Binding Informal NRC

$$
(q=0)
$$

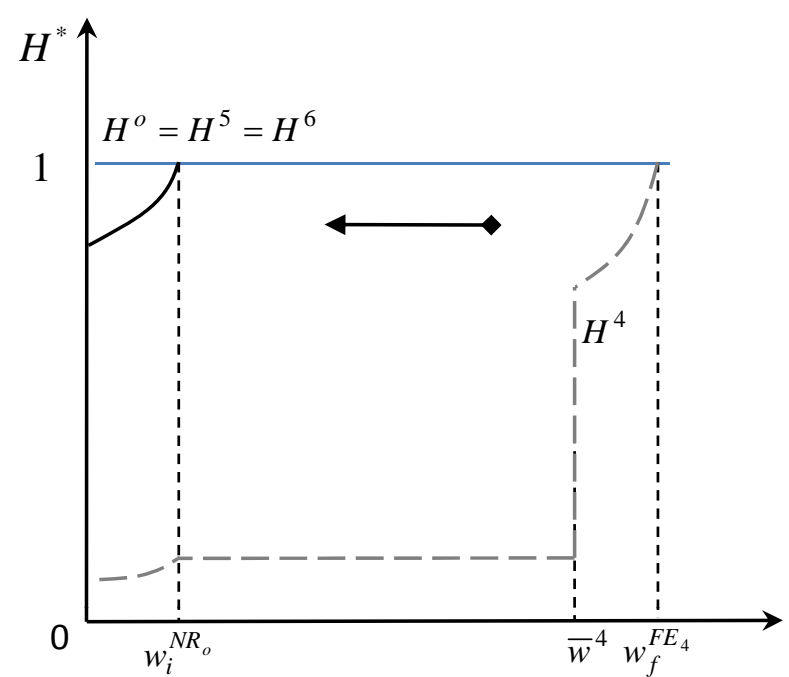

Figure 6c

Minimum Wage with a Binding Informal NRC

$(q=0)$ 